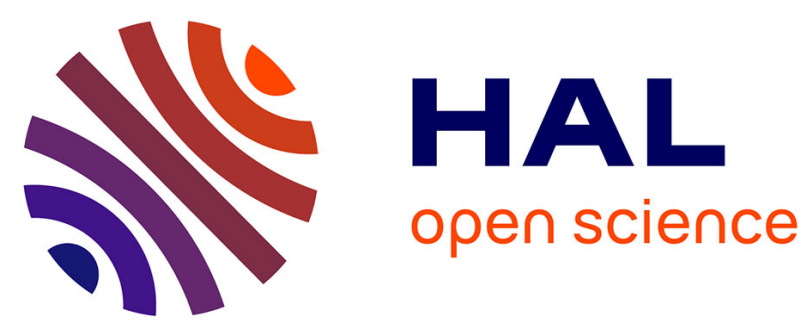

\title{
Experimental Characterization of Commercial and Synthesized Aromatic Polyamide Films for Reverse Osmosis Membranes
}

Xuefan Song, Wafa Guiga, Bernard Rousseau, Anne Jonquieres, Raphaël

Weil, Marion Grzelka, Jehan Waeytens, Alexandre Dazzi, Diana Dragoe,

Claire Fargues

\section{To cite this version:}

Xuefan Song, Wafa Guiga, Bernard Rousseau, Anne Jonquieres, Raphaël Weil, et al.. Experimental Characterization of Commercial and Synthesized Aromatic Polyamide Films for Reverse Osmosis Membranes. Industrial and engineering chemistry research, 2021, 60 (7), pp.2898-2910. 10.1021/acs.iecr.0c05393 . hal-03222083

\section{HAL Id: hal-03222083 \\ https://hal.univ-lorraine.fr/hal-03222083}

Submitted on 17 Nov 2021

HAL is a multi-disciplinary open access archive for the deposit and dissemination of scientific research documents, whether they are published or not. The documents may come from teaching and research institutions in France or abroad, or from public or private research centers.
L'archive ouverte pluridisciplinaire HAL, est destinée au dépôt et à la diffusion de documents scientifiques de niveau recherche, publiés ou non, émanant des établissements d'enseignement et de recherche français ou étrangers, des laboratoires publics ou privés. 


\section{Experimental characterization of commercial and synthesized aromatic polyamide films for reverse osmosis membranes}

Xuefan SONG ${ }^{1,3}$, Wafa GUIGA ${ }^{1,2}$, Bernard ROUSSEAU ${ }^{3}$, Anne JONQUIERES ${ }^{4}$, Raphaël WEIL ${ }^{5}$, Marion GRZELKA ${ }^{5}$, Jehan WAEYTENS ${ }^{3,7}$, Alexandre DAZZI ${ }^{3}$, Diana DRAGOE $^{6}$, Claire FARGUES ${ }^{1 *}$

1 Université Paris-Saclay, INRAE, AgroParisTech, UMR SayFood, 91300, Massy, France ${ }^{2}$ Conservatoire National des Arts et Métiers, 75003, Paris, France

${ }^{3}$ Université Paris-Saclay, CNRS, Institut de Chimie Physique UMR8000, 91405, Orsay, France

${ }^{4}$ Université de Lorraine, CNRS, Laboratoire de Chimie Physique Macromoléculaire (LCPM) UMR 7375, 54001, Nancy, France

${ }^{5}$ Université Paris-Saclay, CNRS, Laboratoire de Physique des Solides UMR8502, 91405, Orsay, France

${ }^{6}$ Université Paris-Saclay, CNRS, ICMMO UMR8182, 91405 Orsay, France

${ }^{7}$ Structure et Fonction des Membranes Biologiques, Université libre de Bruxelles, 1050 Bruxelles, Belgique

* Corresponding author: Claire FARGUES, AgroParisTech, UMR 782 SayFood, 1 av. des Olympiades, F-91300 Massy, France.

Phone: +33 (0)1 699350 95; Fax: +33 (0)1 699350 44;

claire.fargues@agroparistech.fr 


\section{ABSTRACT}

The complex structure of the active aromatic polyamide (APA) layer of reverse osmosis membranes needs to be precisely described for understanding and predicting solutes rejection. A commercial reverse osmosis membrane (CPA2-Hydranautics) was chosen as a case-study, and home-made APA films prepared by free-standing interfacial polymerization of trimesoyl chloride (TMC) and $m$-phenylenediamine (MPD), at different temperatures in order to obtain different film structures. Their morphology, thickness, void fraction, density and chemical composition were characterized with scanning electron microscopy (SEM), atomic force microscopy (AFM), profilometry, ellipsometry, dynamic vapor sorption (DVS) and X-ray Photoelectron Spectroscopy (XPS). All samples have a multi-level topological structure as a dense base upon which generates: a valley-ridge structure for CPA2 and a chimney-like structure for synthesized samples, whose thicknesses increase with temperature. An average void fraction of $35 \%$ was deduced for the APA from CPA2, allowing the calculation of a dry density of its dense phase of $1.24 \mathrm{~g} \cdot \mathrm{cm}^{-3}$, rarely investigated for commercial membranes. New chemical descriptors considering chain heads, tails and branches were introduced to improve the interpretation of chemical composition results. More realistic than the cross-linking degree, they suggested for CPA2 active layer a back-surface chemically less cross-linked than the topsurface. 


\section{INTRODUCTION}

Reverse osmosis (RO) is extensively used for pure water production and industrial wastewater treatment in various fields ${ }^{1-4}$, due to advantages such as continuity, easy scaling-up, minimum consumption of chemicals and absence of toxic by-products ${ }^{5,6}$. Its broad applicability in industrial wastewater treatment includes the removal of trace levels of micro pollutants, such as pharmaceutical compounds ${ }^{7,8}$ and pesticides ${ }^{9,10}$.

However, rejection and transfer's behavior of small neutral organic components (molecular weight $(M W)<180 \mathrm{~g} / \mathrm{mol}$ ) remain difficult to predict. Previous studies showed that organics rejection was affected not only by molecular weight or size but also by specific solutemembrane interactions ${ }^{11-16}$ linked to solutes' as well as membranes' chemical properties. For these membranes, the top-layer in cross-linked aromatic polyamide (APA, thickness $\sim 200 \mathrm{~nm}$ ), interfacially polymerized on a microporous polysulfone (PSf) support, dominates membrane selectivity. A solution-diffusion model commonly represents the transfer through it. ${ }^{17-19}$ The complex structure of the APA layer needs to be precisely described for understanding and predicting solutes rejection. This requires the determination of several key parameters, notably thickness, density, roughness, voids fraction, cross-linking degree, etc. ${ }^{20,21}$ Scanning electron microscopy (SEM), transmission electron microscopy (TEM), and atomic force microscopy (AFM) applied on APA surface and cross-section shed light on the thickness, morphology and roughness information ${ }^{22-31}$ while spectroscopic ellipsometry and quartz crystal microbalance ${ }^{23,32-34}$ allow to access to the void fraction in this layer, crucial to determine accurately the density of the dense APA phase, excluding voids. X-ray photoelectron spectroscopy (XPS), ${ }^{23,32,35-37}$ Rutherford back scattering (RBS) ${ }^{33,38,39}$ and Fourier transform infrared spectroscopy (FTIR) ${ }^{26,36}$ also help in understanding whether the polymerization conditions affect the layer's chemical structure. Indeed, a depth-dependent heterogeneous structure was found, ${ }^{22,23,38}$ probably due to $m$-phenylenediamine (MPD) monomer concentration evolution along its diffusion direction during the supported interfacial polymerization. Moreover, Nguyen et al. ${ }^{40}$ showed that membranes with different characteristics (thickness, isoelectric point...) 
41,42 could nevertheless lead to similar performances, as ESPA2 and NF90 membranes for glucose, xylose, acetic acid, furfural or HMF rejections. A case-to-case study remains therefore essential if a structure-property relationship investigation is intended for a given RO membrane.

In this work, the uncoated and fully-aromatic commercial RO membrane CPA2 (Hydranautics, Nitto Group Company, USA), whose rejection performances and sorption properties were extensively studied in our team ${ }^{4,12,40,43,44}$ was chosen as case-study. A better description of APA structure of commercial membranes is invaluable to improve transfer understanding at molecular level. In order to compare its structural properties to those of membranes obtained under constrained conditions, free-standing home-made APA films were synthesized at different temperatures, in order to vary the kinetics and the film structure, as reported by Korshidi et al. ${ }^{21}$ For all samples, morphology and roughness analyses were conducted via SEM, AFM and profilometry. Thickness was investigated via AFM and profilometry, and spectroscopic ellipsometry was used to search for the void fraction in APA layer of CPA2, leading to an estimation of two important parameters for the membrane properties, i.e. its effective density, as well as that of the dense APA phase. Its chemical composition was also investigated via XPS using new chemical descriptors, which consider chain heads, tails and branches for going beyond the classical description of cross-linking degree and further improve the structural characterization of these complex APA systems.

\section{MATERIALS AND METHODS}

\subsection{Chemicals}

All reagents and chemicals were of analytical grade and were used as received: sodium metabisulfite $\left(\mathrm{Na}_{2} \mathrm{~S}_{2} \mathrm{O}_{5}\right.$, Sigma-Aldrich), potassium nitrate $\left(\mathrm{KNO}_{3}\right.$, Sigma-Aldrich, $\left.\geq 99 \%\right)$, ammonium chloride $\left(\mathrm{NHCl}_{4}\right.$, Sigma-Aldrich $\left.\geq 99.5 \%\right)$, sodium bromide ( $\mathrm{NaBr}$, VWR Prolabo, $100 \%$ ), sodium iodide (Nal, Sigma-Aldrich, $\geq 99 \%$ ), potassium hydroxide ( $\mathrm{KOH}$, Sigma- 
Aldrich, $\geq 85 \%$ ), trimesoyl chloride (TMC, Sigma-Aldrich, $98 \%$ ), m-phenylenediamine (MPD, Sigma-Aldrich, $99 \%$ ), triethylamine (TEA, Sigma-Aldrich, $\geq 99 \%$ ), N,N-dimethylformamide (DMF, Sigma-Aldrich, $\geq 99.9 \%$ ), chloroform (stabilized with ethanol, Carlo Erba, $\geq 99 \%$ ), $n$ hexane (Carlo Erba, analytic grade for HPLC). Ultrapure water was produced in the laboratory via MilliQ water system (resistivity > $18 \mathrm{M} \Omega . \mathrm{cm}$, Millipore).

\subsection{APA layer preparation}

\subsubsection{APA layer isolation from commercial RO CPA2 membrane}

CPA2 RO membrane was purchased from Hydranautics (Nitto Group Company, USA) as spiral wound module in wet state. Its active layer is made of uncoated and fully aromatic polyamide. Membrane samples were initially cut into A4 coupons, rinsed with pure water, then stabilized with $1 \%$ sodium metabisulfite solution and conserved at $4{ }^{\circ} \mathrm{C}$ under vacuum. Before using it, the membrane was rinsed by $\mathrm{KOH}$ at $0.4 \mathrm{~g} \mathrm{~L}^{-1}$ and then by ultrapure water until reaching neutral $\mathrm{pH}$. Polyester layer was peeled, leading to the ensemble PSf+APA, from which APA was isolated.

The back-surface, named 'CPA2-bs', was obtained following the methodology developed by Freger (2004) ${ }^{45}$ and extensively used since then. Few changes were made to this original methodology: chloroform was first used instead of DMF (more harmful) to dissolve PSf. Then only few droplets of DMF completed the removal of PSf, allowing to swell and soften the APA layer, preventing its deformation such as folding before recovery. Then the layer stayed flat on the wafer. ${ }^{45}$ Dissolution was considered finished when the layer remained completely transparent after solvent evaporation.

To obtain the APA top-surface, named 'CPA2-ts', the PSf + APA coupon was immersed in DMF solvent with the help of a clip fixing the two opposite sides of the coupon with the APA surface facing up. The PSf was completely dissolved in a progressively renewed DMF bath. Only little trace of PSf remained in the solvent in the end according to XPS analysis. The obtained APA film was recovered by introducing underneath a silicon wafer of $1 \times 1 \mathrm{~cm}^{2}$ and 
then raised out from the liquid. The APA + wafer ensemble was air-dried and then conserved at $4{ }^{\circ} \mathrm{C}$ out of direct light for future analyses.

\subsubsection{APA layer synthesis}

The free-standing aromatic polyamide film samples were synthesized via interfacial polymerization from TMC and MPD following precedent methodologies ${ }^{20,46-48}$. The monomer concentrations and the organic solvent ( $n$-hexane) used were typical for the TMC/MPD systems ${ }^{20,48,49}$. The volume of the aqueous phase was the same as that reported by Cui et al. ${ }^{46}$ and the volume of the organic phase was adapted to the Petri dish size to ensure good covering of the aqueous phase by the TMC organic solution. $20 \mathrm{~mL}$ of MPD aqueous solution $(3 \% \mathrm{w} / \mathrm{v})$ containing $1 \% \mathrm{w} / \mathrm{v}$ TEA was poured into a Petri dish (diameter: $8.5 \mathrm{~cm}$ ). Then $10 \mathrm{~mL}$ of TMC (1\%w/v) $n$-hexane organic solution was added delicately upon the aqueous surface with the help of a glass plate (size: $2 \mathrm{~cm} \times 5.5 \mathrm{~cm}$ ) to avoid eddies. The Petri dish was then covered with a glass plate to limit solvent evaporation during interfacial polymerization. 15 minutes contact time was necessary to obtain enough APA quantity. Such reaction time is consistent with other authors. ${ }^{20,32,47,48} \mathrm{~A}$ continuous film was obtained at the interface and the polymerization reaction was stopped: the upper organic solution and lower aqueous phase were removed, while $2 \mathrm{~mm}$ depth of aqueous phase was maintained to avoid the film adhesion to the Petri dish bottom. Then, the top-surface was rinsed three times with $20 \mathrm{~mL} n$-hexane and the back-surface three times with $20 \mathrm{~mL}$ ultrapure water, on always keeping a thin layer of water at the end of each washing step to let the synthesized film float on its surface. The interfacial polymerizations were carried out at three temperatures (-20 (cryostat), 0 (ice bath) and $29^{\circ} \mathrm{C}$ (ambient temperature)). Initial aqueous and organic solutions were maintained as close as possible to the target temperature. For the synthesis at $-20^{\circ} \mathrm{C}$, the aqueous solution temperature was maintained at around $0^{\circ} \mathrm{C}$ to avoid freezing of the aqueous phase. The synthesized samples were labelled in the form of 'Syn'+'synthesis temperature' as Syn $-20^{\circ} \mathrm{C}$, Syn $0{ }^{\circ} \mathrm{C}$ and Syn $29^{\circ} \mathrm{C}$. 
For SEM, AFM, profilometry and XPS characterizations, the CPA2 and synthesized film samples were all prepared on a silicon wafer around $1 \times 1 \mathrm{~cm}^{2}$, and the analyses were realized far from the edges where the film may be folded or damaged, impacting thickness and chemical composition.

\subsection{Structural characterizations}

\subsubsection{Morphology and thickness analysis: field emission scanning electron microscopy (FE-SEM), atomic force microscopy (AFM) and profilometry}

FE-SEM and AFM analyses were performed on APA top- and back-surface of all dry samples.

- $\quad$ FE-SEM (Zeiss SUPRA55-VP) was used with 2 secondary electron detectors, an inlens and an Everhart-Thornley SE detector. Samples were mounted onto the steel mesh without usual sputter-coating and then put under vacuum for the analysis. The analysis was performed under $1.5 \mathrm{kV}$ to reduce the charging effect, at magnification of 4000 . SmartSEM® software was used for data acquisition.

AFM analyses were performed with a nanoIR2 system (Bruker nano, USA) to obtain the height profile (or peak-to-valley distance) of the samples placed on a silicon wafer, to study thickness, morphology and roughness. The measures were done in contact mode, with a goldcoated tip (30 nm diameter) (HQ: CSC38/CR-AU, MicroMasch) with a constant force around $20 \mathrm{nN}$. Data acquisition was realized with the software Analysis Studio (version 3.15, Bruker nano, USA), and the images and data treated with Analysis Studio and MountainsMap® (Version 8, Digital Surf, France).

For thickness measurement $\left(\delta_{\mathrm{AFM}}\right)$, frame leveling was realized via the MountainsMap's 'Series of profile' analysis, which adjusted the cross-section height profile of blank wafer on horizontal level, line by line. Each point height in $\mathrm{X}, \mathrm{Y}$ plane was defined as $Z_{i j}=Z\left(X_{i}, Y_{j}\right)$. With $\mathrm{N}_{\mathrm{x}}$ and $\mathrm{N}_{\mathrm{y}}$ the number of points in $\mathrm{X}, \mathrm{Y}$ dimensions of a target area, the average height of the area is calculated as:

$$
\mu=\frac{1}{\mathrm{~N}_{\mathrm{x}} \cdot \mathrm{N}_{\mathrm{y}}} \sum_{\mathrm{j}=1}^{\mathrm{N}_{\mathrm{y}}} \sum_{\mathrm{i}=1}^{\mathrm{N}_{\mathrm{x}}} \mathrm{Z}_{\mathrm{ij}}
$$


The heights of blank wafer $\left(\mu_{\text {wafer }}\right)$ and film region $\left(\mu_{\text {film }}\right)$ on avoiding the edge (the film region within at least $2 \mu \mathrm{m}$ distance is not analyzed) were calculated independently and the difference between them defined as the average film thickness measured by AFM $\left(\delta_{A F M}=\mu_{\text {film }}-\mu_{\text {wafer }}\right)$. Besides, the morphology (peak-to-valley distance distribution or height histogram) was analyzed on a detection region of film around $10 \times 10 \mu \mathrm{m}^{2}$ area. The statistic roughness was quantified from 10 repetitions of $5 \times 5 \mu \mathrm{m}^{2}$ selections and calculated as:

$$
\mathrm{S}_{\mathrm{q}}=\sqrt{\frac{1}{\mathrm{~N}_{\mathrm{x}} \cdot \mathrm{N}_{\mathrm{y}}} \sum_{\mathrm{j}=1}^{\mathrm{N}_{\mathrm{y}}} \sum_{\mathrm{i}=1}^{\mathrm{N}_{\mathrm{x}}}\left(\mathrm{Z}_{\mathrm{ij}}-\mu\right)^{2}}
$$

$S_{q}$ uncertainty was evaluated by the confidence interval at $95 \%$ confidence on the 10 repetitions.

Cross-section profiles of all top-surfaces were also extracted from AFM analyses of a $10 \times 30 \mu \mathrm{m}^{2}$ or $30 \times 30 \mu \mathrm{m}^{2}$ surface of a half film-covered region on the silicon wafer. The height was recorded along at least 16 different lines. An evaluation of the base thickness $\left(\delta_{\text {base }}\right)$ upon which roughness or irregularities develop was estimated as the lowest level of the valleys detected by the AFM tip, and averaged for the different lines analyzed per sample. For CPA2, its back-surface was also analyzed.

- $\quad$ Profilometry (DektakXT, Bruker, Germany) was applied to investigate the APA film thickness of CPA2-ts, CPA2-bs and synthesized samples' top-surface. Influence of the relative humidity $(\mathrm{RH})$ on the film thickness ( $\left.\delta_{\text {Pro }}\right)$ was investigated. Each sample was placed in $95 \%$, $79 \%, 59 \%, 40 \%$ and $9 \% \mathrm{RHs}$ at $20{ }^{\circ} \mathrm{C}$ using over-saturated salt solutions of potassium nitrate, ammonium chloride, sodium bromide, sodium iodide or potassium hydroxide, respectively..$^{50}$ An incubation time of 7 days ensured the water sorption equilibrium. Just before analysis, the sample was taken out from the conditioned environment onto the profilometry device in a chamber at ambient humidity (absence of $\mathrm{RH}$ control during analysis time). For each sample, between 4 to 10 lines were analyzed with a total analysis duration less than 10 min. However, between the first and the last analyzed line, no evident thickness evolution was 
observed, thanks to the short analysis time. $S_{q}$ analysis of profilometry was only performed at $9 \% \mathrm{RH}$.

The analyses were realized with a force of $1 \mathrm{mg}$ and a tip diameter of $4 \mu \mathrm{m}$. Data acquisition and treatment were performed via software Bruker Vision 64. In this study, data were saved with a spatial resolution of $0.11 \mu \mathrm{m}$, except for the sample conditioned at $95 \%$ relative humidity $(\mathrm{RH})$, where the resolution was $1.11 \mu \mathrm{m}$. The vertical height profile of a straight line around 2 $\mathrm{mm}$ long, crossing half wafer and half sample region, was analyzed, on which $100 \mu \mathrm{m}$ or 200 $\mu \mathrm{m}$ regular and flat regions of sample and silicon wafer profile were selected. As for AFM, ठro was calculated as the difference between the average sample and wafer heights of the selected region. Thickness and roughness $\left(S_{q}\right)$ uncertainties were evaluated by a $95 \%$ confidence interval for at least 4 lines.

\subsubsection{Void fraction estimation by spectroscopic ellipsometry analysis}

Spectroscopic ellipsometry (Accurion EP3) was used to determine the refractive index $\left(\mathrm{n}_{\text {film }}\right)$ of the APA layer and deduce its void fraction. Analysis was carried out on dry samples $(2 \%(\mathrm{w} / \mathrm{w})$ water content) obtained after conditioning at $9 \% \mathrm{RH}$ for 7 days. The sample was taken out from the conditioned environment onto the ellipsometry device before each analysis. Each analysis was launched immediately at ambient humidity and lasted for less than $10 \mathrm{~min}$. Since the water sorption or desorption kinetics was rather slow and corresponded to a low weight gain or loss $(3 \%, w / w)$ in 10 min, it was considered that the presence of low water content did not interfere in the exploitation of the ellipsometry results. Duplicate samples on silicon wafers were prepared and at least 5 locations were analyzed on each. Data acquisition was performed via software EP3View V235 and data modelling was via EP4Model 1.01.

Ellipsometry measures changes in light beam polarization upon specular reflection of the sample, as the ratio of the reflectivity of polarized light in plane $\left(r_{p}\right)$ and out of plane $\left(r_{s}\right)$. The light focusing optics allow adjusting the polarization and offer an optimum condition for the analysis. A multi-layer optical model is used to obtain the refractive index of the material by fitting reflectivity ratio $\left(r_{p} / r_{s}\right)$ with respect to angle of incidence $\left(A O I,{ }^{\circ}\right)$ and wavelength of 
analysis $(\lambda, \mathrm{nm})$. Silicon wafer was modeled as a $2 \mathrm{~nm}$ silicon dioxide layer (that had been measured independently) and an infinite silicon bottom layer. Each optical layer was described by its thickness $(\delta)$, absorption index $(k)$ and refractive index $(n)$. Two AOI values were used $\left(60^{\circ}\right.$ and $\left.70^{\circ}\right)$ and the laser beam wavelength was $658 \mathrm{~nm}$. Optical properties for middle and bottom layers were taken as $\mathrm{n}=1.456, \mathrm{k}=0$ and as $\mathrm{n}=3.829, \mathrm{k}=0.014$ respectively. For APA layer, its thickness was preset as the previously obtained $\delta_{\text {AFM }}$ or $\delta_{\text {Pro, }}$, and only $n_{\text {film }}$ was fitted assuming $\mathrm{k}_{\mathrm{APA}}=0$. The model fitting was accepted when root-mean-square error (RMSE) was smaller than 100 .

According to effective-medium approximation (EMA) models, the void fraction ( $\left.f_{\text {void }}\right)$ of APA film was deduced based on the obtained effective refractive index $\left(\mathrm{n}_{\text {film }}\right)$, the pure dense APA polymer refractive index $\left(n_{\text {polymer }}=n_{\text {APA }}\right)$ and that of void $\left(n_{\text {void }}=n_{\text {air }}=1\right)$, by applying the following models:

Parallel Model:

$$
\mathrm{n}_{\text {film }}=\left(1-\mathrm{f}_{\text {void }}\right) \mathrm{n}_{\text {polymer }}+\mathrm{f}_{\text {void }} \mathrm{n}_{\text {void }}
$$

Series Model:

$$
\frac{1}{\mathrm{n}_{\mathrm{film}}}=\frac{1-\mathrm{f}_{\text {void }}}{\mathrm{n}_{\text {polymer }}}+\frac{\mathrm{f}_{\text {void }}}{\mathrm{n}_{\text {void }}}
$$

Bruggeman Model:

$$
1-\mathrm{f}_{\text {void }}=\frac{\frac{\mathrm{n}_{\text {film }}^{2}}{\mathrm{n}_{\text {polymer }}^{2}}-\frac{\mathrm{n}_{\text {void }}^{2}}{\mathrm{n}_{\text {polymer }}^{2}}}{\left(\frac{\mathrm{n}_{\text {film }}^{2}}{\mathrm{n}_{\text {polymer }}^{2}}\right)^{1 / 3}\left(1-\frac{\mathrm{n}_{\text {void }}^{2}}{\mathrm{n}_{\text {polymer }}^{2}}\right)}
$$

The choice for pure dense APA polymer refractive index ( $n_{\text {polymer }}$ ) is discussed in the Results section. Uncertainty on $\mathrm{f}_{\text {void }}$ was estimated by the average variation between average value and maximum or minimum ones, issued from the error on $\mathrm{n}_{\text {film }}$ analysis. 


\subsubsection{Density estimation}

Samples' mass and their water uptake were measured by dynamic vapor sorption device (DVS, Intrinsic instrument). In order to obtain a sufficient mass, enough polymer films had to be gathered softly into a pellet, which corresponds to several hundreds of $\mathrm{cm}^{2}$ due to the extreme thinness of the film.

For APA from CPA2, several dissected films with accurate known surface were progressively gathered in a glass vial, then generously rinsed by ultrapure water via filtration on a nylon filter and recovered gently together as a pellet with the help of a plastic tweezer. For the homemade APA films, each of them was prepared in a Petri dish (diameter: $8.5 \mathrm{~cm}$ ) as described in 2.2.2. The floating entire surface was recovered from the rinsing water and gathered together softly as a pellet.

The samples were first conditioned in dry state then transferred into a dynamic vapor sorption device (DVS, Intrinsic instrument) to measure precise masses at controlled $\mathrm{RH} \%$ (systematic fluctuation of $\pm 0.5 \%$ ). $0 \%$ and $95 \% \mathrm{RH}$ were used to search for the dry and hydrated densities. For each $\mathrm{RH}$ stage, equilibrium time was set as $24 \mathrm{~h}$ for $\mathrm{CPA} 2$ samples and $48 \mathrm{~h}$ for synthesized ones. The dry mass of the samples was between 2.4 and $9 \mathrm{mg}$.

Considering the heterogeneity of the APA films, three density concepts were investigated to get a more complete understanding of the film structure and dense APA polymer property. Mass of the material $(\mathrm{m}, \mathrm{g})$ and film surface $\left(\mathrm{S}, \mathrm{cm}^{2}\right)$ of thickness $\delta(\mathrm{cm})$ lead to:

- the areal density:

$$
\mathrm{d}_{\text {areal }}=\frac{\mathrm{m}}{\mathrm{s}} \quad\left(\mathrm{g} \cdot \mathrm{cm}^{-2}\right)
$$

- the effective volumetric density of the film, which includes voids:

$$
\mathrm{d}_{\mathrm{film}}=\frac{\mathrm{d}_{\mathrm{areal}}}{\delta} \quad\left(\mathrm{g} \cdot \mathrm{cm}^{-3}\right)
$$

- the volumetric density of the dense APA region (excluding voids), or referring to the void-free dense phase: 


$$
\mathrm{d}_{\mathrm{APA}}=\frac{\mathrm{d}_{\mathrm{film}}}{\left(1-\mathrm{f}_{\mathrm{void}}\right)}\left(\mathrm{g} \cdot \mathrm{cm}^{-3}\right)
$$

For CPA2, the total surface $(\mathrm{S})$ corresponding to the obtained film mass $(\mathrm{m})$ was measured precisely by the ruler before the dissection. For the synthesized films, since they were considered fully recovered after the synthesis the considered surface $S$ was taken as the total known surface of the Petri dish.

Uncertainties were estimated by the variation between the average and the maximum or minimum values.

\subsubsection{X-ray photoelectron spectroscopy}

The chemical compositions of CPA2 original top-surface, CPA2-bs and CPA2-ts samples were obtained by a ThermoFisher Scientific K-Alpha XPS spectrometer equipped with a monochromatic aluminum source $\left(\mathrm{Al} \mathrm{K}_{\alpha}, \mathrm{hv}=1486.68 \mathrm{eV}\right)$ under ultrahigh vacuum condition $\left(10^{-7} \mathrm{~Pa}\right)$. Samples were previously rinsed thoroughly with ultrapure water and air-dried. The emission angle was set to $0^{\circ}$ with an analysis depth up to $10 \mathrm{~nm}$, the $\mathrm{X}$-ray gun was operated at $10 \mathrm{kV}$ and charge neutralization system was used. The survey spectra acquisition was realized with a sweeping range over $0-1350 \mathrm{eV}$, a pass energy of $100 \mathrm{eV}$ and an energy step of $1 \mathrm{eV}$.

For each sample, at least 2 frames of $1 \mathrm{~cm}^{2}$ area were studied, and on each frame at least 3 irradiated zones of about $1 \mathrm{~mm}^{2}$ were analyzed, leading to between 6 and 14 studied zones. The elemental percentages were obtained from the photoelectron peak area using the Avantage and CasaXPS softwares after a Shirley type background subtraction and following normalizations of the peak areas with the Scofield sensitivity factors. The initial raw data were treated on eliminating the chemical compositions from the impurities. Notably, for samples of CPA2, when a small amount of sulfur from PSf was detected, the associated oxygen and carbon contents were eliminated on the basis of PSf's $\left(\mathrm{C}_{27} \mathrm{O}_{4} \mathrm{SH}_{22}\right)_{n}$ chemical formula. All data were compared and averaged to ensure the sample representativeness. 


\section{RESULTS AND DISCUSSION}

\subsection{Morphology}

CPA2 original top-surface observed via SEM appears rather "regular"; however, some images highlight the presence of large nodes zones (Figure 1). The selection of a representative region is crucial for further analyses, hence only "regular" regions were selected and compared. Whatever the sample, SEM and AFM methods lead to similar images, while AFM provides a higher resolution (Figure 2). CPA2 top-surface exhibits a typical valley-ridge aspect, already reported for other commercial RO membranes ${ }^{51}$ among which ESPA2 and ESPA3 are from the same supplier. ${ }^{24,25,27,52}$ Furthermore, Figure 2 shows that dissection did not damage the APA structure as dissected CPA2-ts is quite similar to the original one. CPA2-bs has a smoother appearance, already noticed for other commercial membranes and explained by the PSf support layer that would prevent the APA's free growth on that side, as well as by the fact that TMC in the organic upper phase is insoluble in the bottom aqueous phase. ${ }^{24,25,53}$

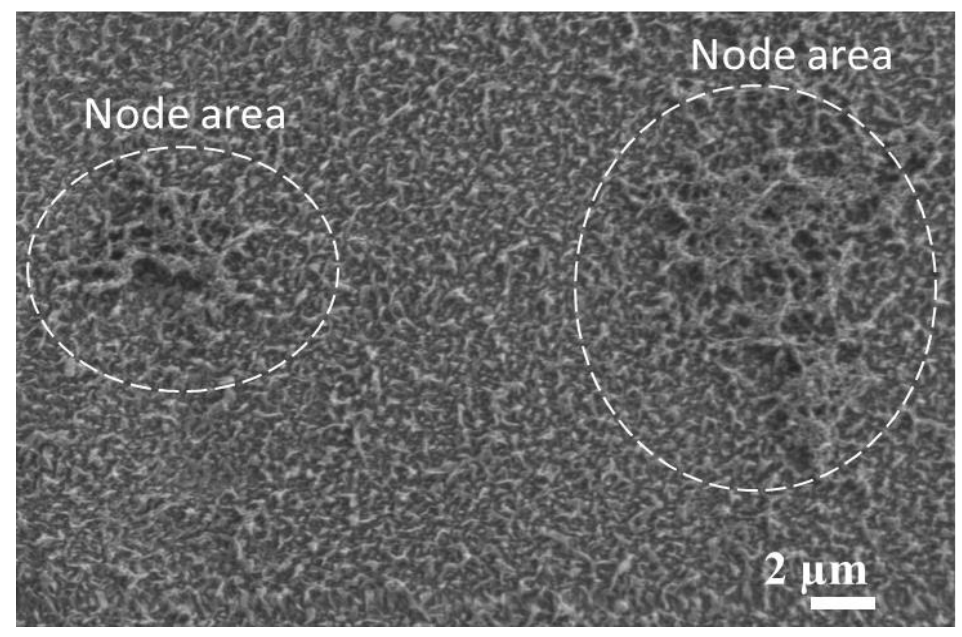

Figure 1. SEM image of CPA2 original APA top-surface 


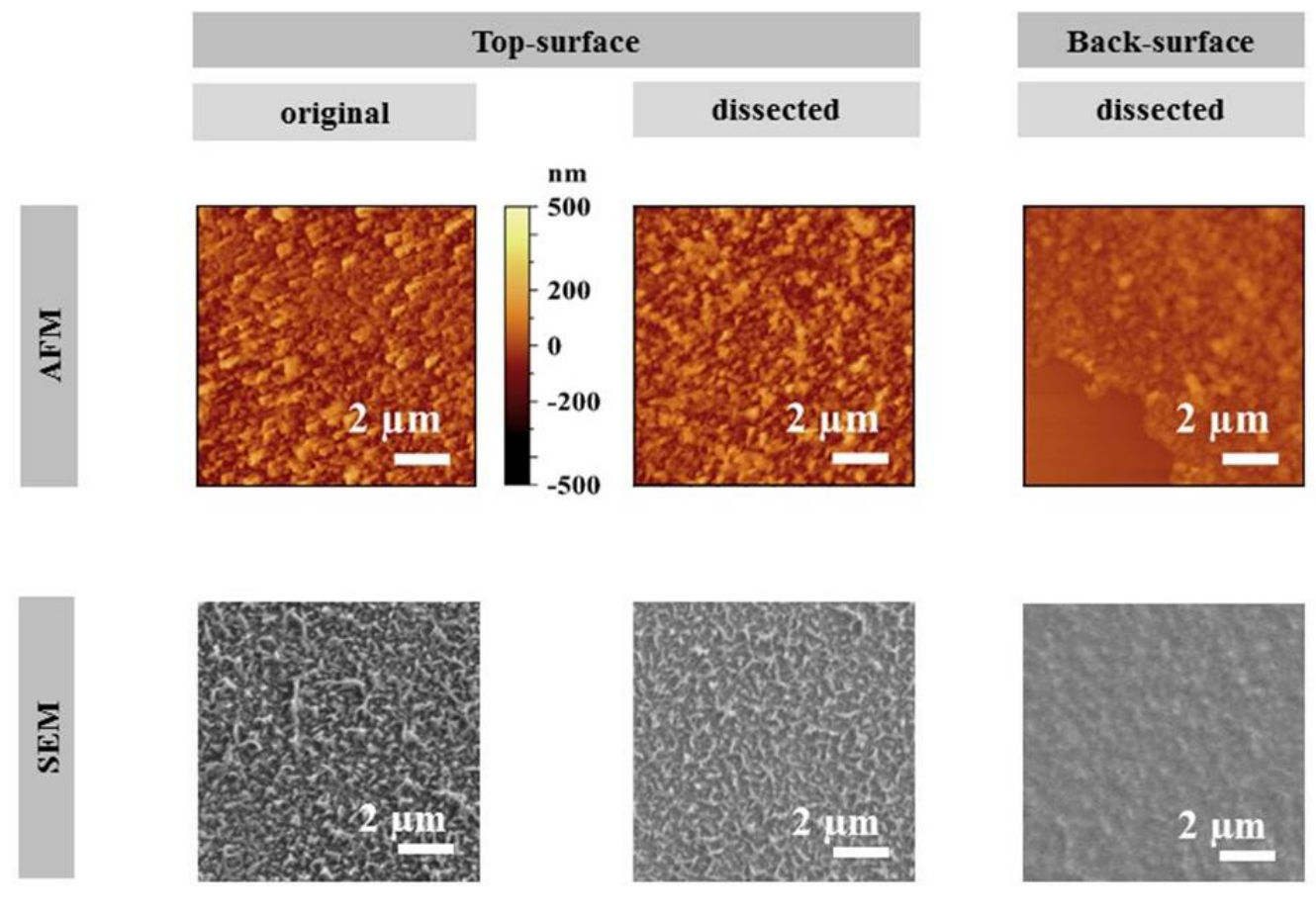

Figure 2. AFM and SEM images of CPA2 APA layers.

Morphology of the free-standing synthesized films is significantly different, presenting hollow cylindrical walls forming open inner cavities, which were referred to as 'chimney-like structures' or 'chimneys' in this study (Figure 3). Even the back-surface, although smoother, appears pitted rather than rough. This smooth back-surface morphology would again illustrate the polymerization limitation towards the bottom aqueous phase.

While the temperature increase does not influence the back-surface aspect, it affects the chimneys size on the top-surface. AFM reveals a "two-levels" or "two-times" polymerization phenomenon at $0{ }^{\circ} \mathrm{C}$, with a base covered by middle-size chimneys (ranging between that for $-20^{\circ} \mathrm{C}$ and for $29^{\circ} \mathrm{C}$ ), covered in few places by "top"-chimneys of larger size. Similar "multilevel" structures have already been observed, for free-standing films at the highest reactant concentrations (MPD concentration from $3 \%$ to $4 \%{ }^{37,46}$, comparable to $3 \%$ here) as well as for supported APA films. ${ }^{32}$ These authors also reported what they called a general "crumpling phenomenon", enhanced with increasing reactant concentrations, especially TMC. ${ }^{46}$ In the present work, the chimneys' size increases with the temperature (except the top-chimneys 
solely observed at $0^{\circ} \mathrm{C}$ ). This observation is consistent with Korshidi's ${ }^{21}$ comment on the influence of synthesis temperature, which would increase the reaction speed and the size of surface features. Furthermore, the polymerization reaction would modify the local temperature, and the resulting thermal gradient consequently lead to Rayleigh-Bénard convection and the creation of local structures, ${ }^{32}$ like the chimneys observed in this work. A complementary explanation could be the rapid dissolution of MPD into the organic phase at the beginning of the free-standing film synthesis, especially due to the high MPD concentration used in the present study. A dense base would then be polymerized at the interface containing enough monomers, while along the diffusion direction (toward the upper organic phase), the MPD concentration would decline progressively, ${ }^{22,54}$ leading to a coverage by small chimneys. The appearance of large "top"-chimneys and formation of a relative thicker base at $0^{\circ} \mathrm{C}$ remained unexplained, and could be due to the difficulty to control the free-standing polyamide synthesis.

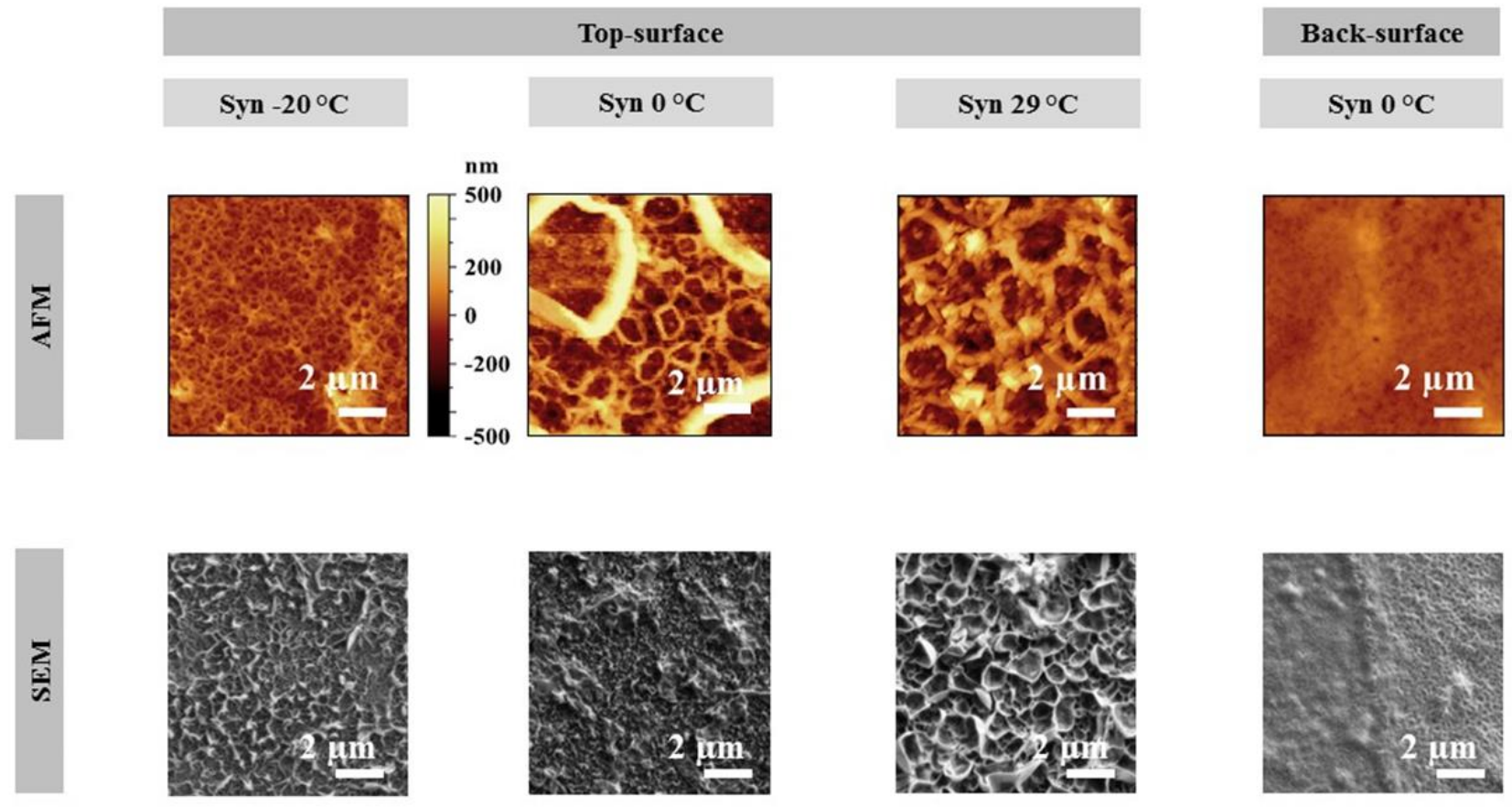

Figure 3. AFM and SEM images of synthesized APA films' top-surface and back surface 


\subsection{Thickness, roughness and structures size}

The analysis of the profilometry profiles and AFM images of each sample led to an estimation of thickness $(\delta)$ and roughness $\left(S_{q}\right)$. Thanks to its thinner tip (30 nm compared to $4 \mu \mathrm{m}$ for the profilometry one), AFM is supposed to fit more precisely the smallest irregularities and thus to describe more accurately the sample roughness. AFM profiles provided:

- $\quad$ an estimation of the base thickness $\left(\delta_{\text {base }}\right)$, on which the irregularities develop;

- the typical size of those irregularities, i.e. the width of a peak (for CPA2 samples), or the diameter and the wall thickness of a chimney (for synthesized samples).

Similar to active layers of other uncoated RO membranes ${ }^{23,45,55}$ no significant swelling was found with $\mathrm{RH}$ for CPA2 analyzed by profilometry (Figure 4), neither for synthesized samples. This was attributed to the rigidity of these highly cross-linked fully aromatic polyamide. For CPA2, back-surface analysis by profilometry leads to a somewhat smaller thickness ( $\delta_{\text {Pro- }}$ $\mathrm{bs}=109 \mathrm{~nm})$ than for top-surface $\left(\delta_{\text {Pro-ts }}=121 \mathrm{~nm}\right)($ Table 1$)$, probably due to a certain compression of the peaks against the wafer surface. However, the difference between both results is within the uncertainty range. The $S_{q}$ analysis showing no significant roughness variation for both surfaces either, hence it was decided to average APA thickness for CPA2 by profilometry as $\delta_{\text {Pro }}=115 \mathrm{~nm}( \pm 4 \mathrm{~nm})$ and its roughness as $S_{q-p r o}=9 \mathrm{~nm}( \pm 1 \mathrm{~nm})$. 


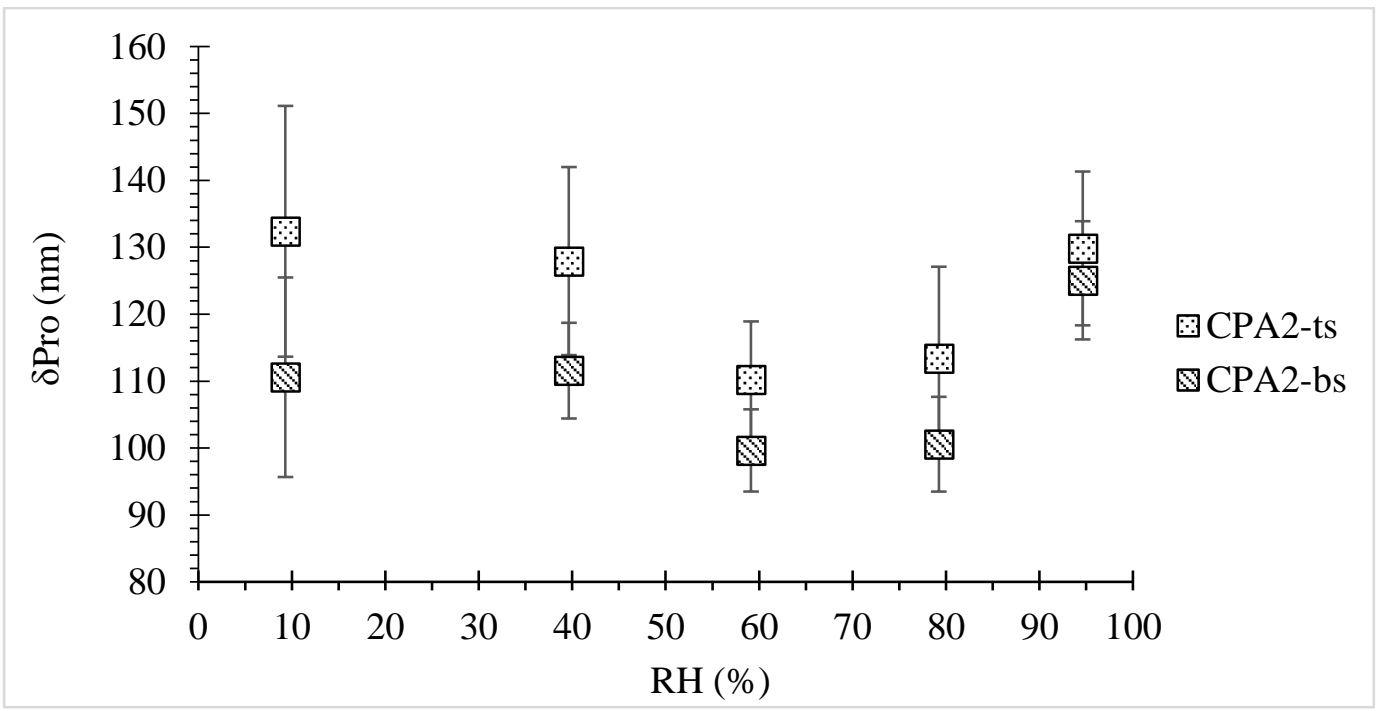

Figure 4. Influence of relative humidity on thickness measured by profilometry for the CPA2 samples

Table 1. Summary of AFM and profilometry characterization of APA films

\begin{tabular}{|c|c|c|c|c|c|c|}
\hline & & \multicolumn{2}{|c|}{ Profilometry } & \multicolumn{3}{|c|}{ AFM } \\
\hline APA film & $d_{\text {typical }}{ }^{a}(\mu \mathrm{m})$ & $\delta_{\text {pro }}(\mathrm{nm})$ & $\mathrm{S}_{\mathrm{q}}(\mathrm{nm})$ & $\delta_{\mathrm{AFM}}(\mathrm{nm})$ & $\delta_{\text {base }}(\mathrm{nm})$ & $\mathrm{S}_{\mathrm{q}}(\mathrm{nm})$ \\
\hline CPA2-ts & $0.2-0.5$ & $121 \pm 7$ & $10 \pm 1$ & $136 \pm 1$ & 40 & $63 \pm 2$ \\
\hline CPA2-bs & - & $109 \pm 5$ & $8 \pm 1$ & $97 \pm 2$ & - & $25 \pm 1$ \\
\hline Syn $-20^{\circ} \mathrm{C}$ & $0.5 \sim 1$ & $300 \pm 30$ & $180 \pm 16$ & $192 \pm 2$ & 60 & $50 \pm 8$ \\
\hline $\operatorname{Syn} 0^{\circ} \mathrm{C}$ & $1 \sim 2 / 6^{b}$ & $344 \pm 25$ & $137 \pm 10$ & $396 \pm 11$ & 160 & $176 \pm 17$ \\
\hline Syn $29^{\circ} \mathrm{C}$ & $2 \sim 3$ & $487 \pm 27$ & $149 \pm 22$ & $368 \pm 15$ & 120 & $117 \pm 5$ \\
\hline
\end{tabular}

a width of the ridges for CPA2-ts; chimney-like structure's diameter for synthesized APA samples.

${ }^{b}$ For Syn $0{ }^{\circ} \mathrm{C}$ sample, two "levels" of chimneys were obtained

With AFM, the gap widens between top and back-surface thicknesses $\left(\delta_{\text {AFM-ts }}=136 \mathrm{~nm}\right.$ against $\delta_{\text {AFM-bs }}=97 \mathrm{~nm}$ ), probably for the same reason as above. Clearly, CPA2-ts profile obtained with AFM is much more irregular than that with profilometry (Figure 5). AFM describes more accurately the smallest details of the area explored (Figure 6) and appears then more adapted to CPA2-ts roughness measurement especially, with a higher $S_{q-t s}=63 \mathrm{~nm}( \pm 2 \mathrm{~nm})$, very close to the XLE's active layer roughness $(=64 \mathrm{~nm})$ obtained by the same technique. ${ }^{33}$ Moreover, and unlike profilometry, its better sensitivity allows distinguishing back from top- 
surface roughness, with $S_{\mathrm{q}-\mathrm{bs}}=25 \mathrm{~nm}( \pm 1 \mathrm{~nm})$. From Figure 6 , a $\delta_{\text {base }}$ of about $40 \mathrm{~nm}$ is obtained, consistent with the literature data for ESPA membranes from the same supplier. ${ }^{24,52}$

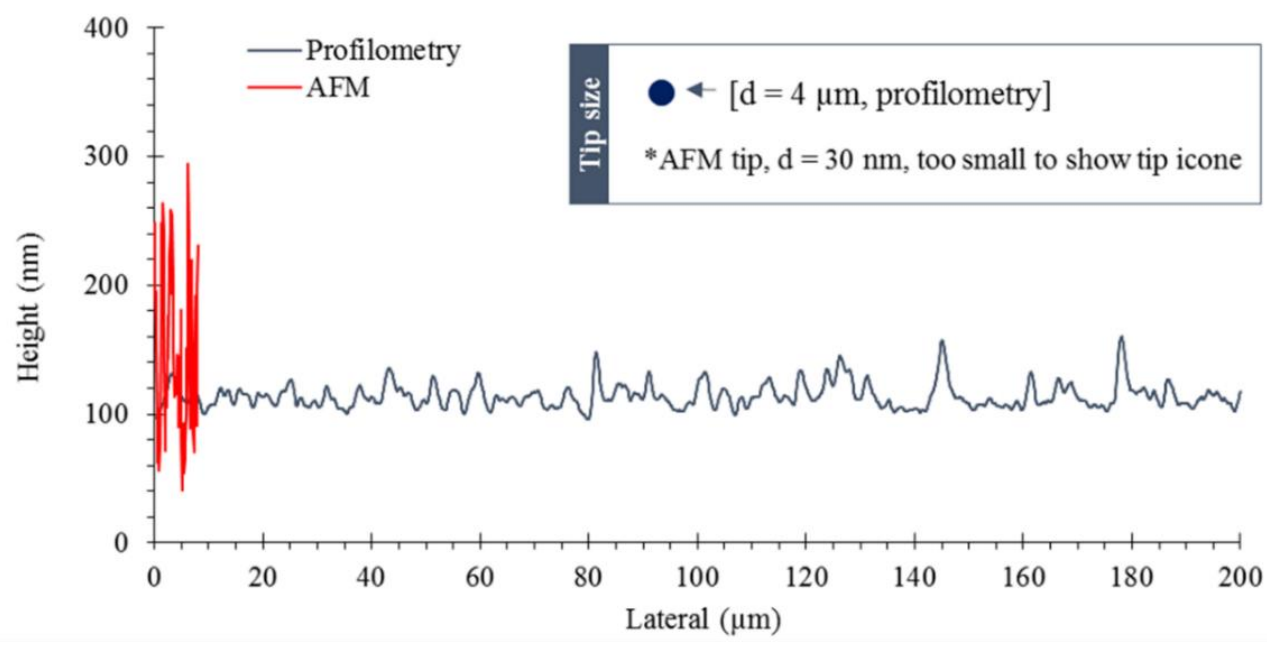

Figure 5. Representative topography profiles of CPA2-ts via profilometry and AFM. Both analyses are realized on distinct sample's frames.

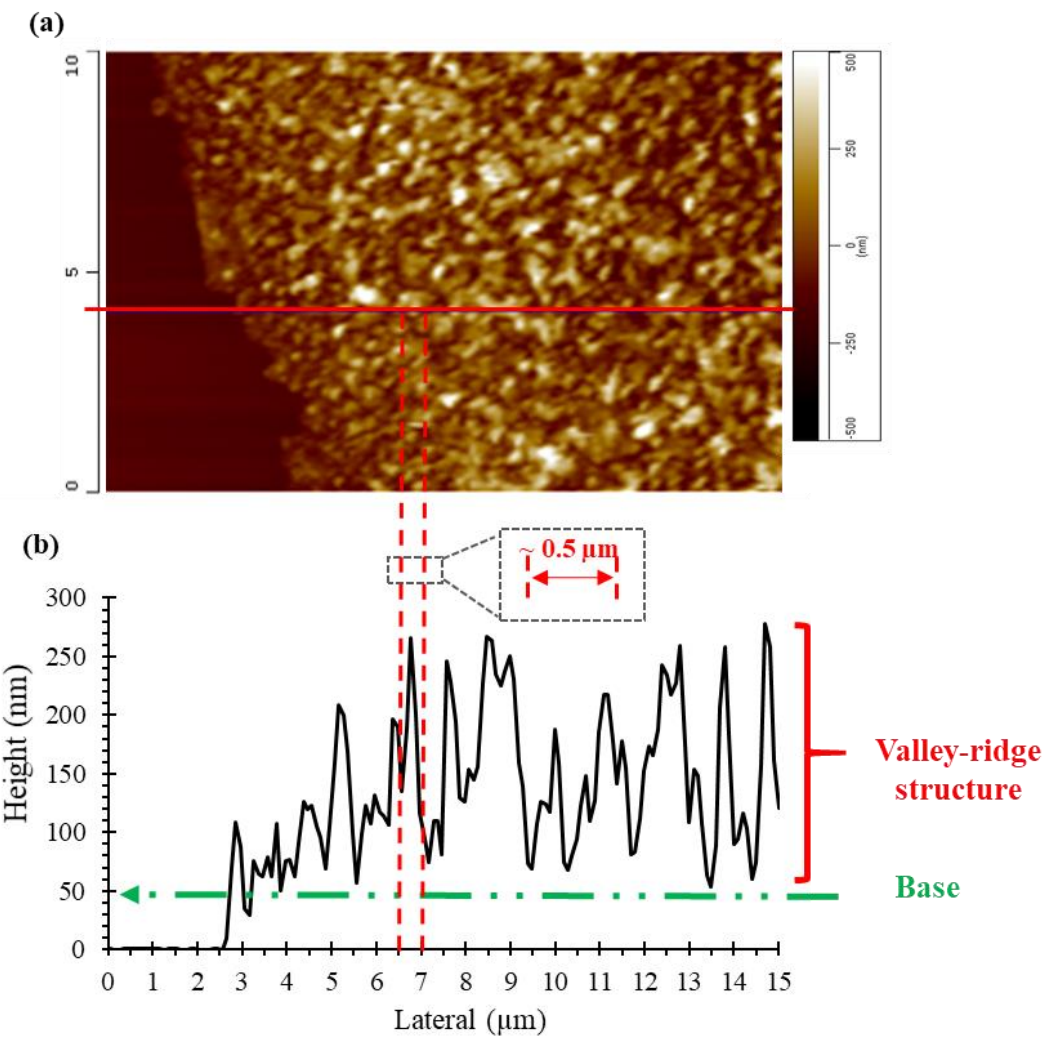

Figure 6. (a): AFM surface images of CPA2-ts; (b): corresponding AFM height profile along the red line. (Analysis of a $10 \times 30 \mu \mathrm{m}^{2}$ half-covered sample). 
For synthesized samples, thickness tends to increase with synthesis temperature, from about $250 \mathrm{~nm}\left(\right.$ at $\left.-20^{\circ} \mathrm{C}\right)$ up to $450 \mathrm{~nm}\left(\right.$ at $\left.29^{\circ} \mathrm{C}\right)$ (Table 1 and Figure 7$)$. Their profiles are very uneven, and the thickness obtained with AFM is smaller than that with profilometry. AFM detailed profile linked to the corresponding image (example for Syn $0^{\circ} \mathrm{C}$ - Figure 8) allows to distinguish a "base" thickness, which also seems to increase with temperature. Above this base lies a first level of chimney-like structures whose outer diameter increases with synthesis temperature from 0.5 to $3 \mu \mathrm{m}$ (Table 1$)$. These elements present thin walls $(0.25 \mu \mathrm{m})$ and relatively small heights (dozens of $\mathrm{nm}$ ). For Syn $0{ }^{\circ} \mathrm{C}$ sample, a second polymerization level has occurred on top of the first one, as can be deduced from Figure $8 \mathrm{c}$ where a complete cycle wall of a small chimney can be observed under part of one large chimney's wall. These larger chimneys have diameter around $6 \mu \mathrm{m}$, as well as thicker and higher walls (thickness around $1 \mu \mathrm{m}$ and height up to $700 \mathrm{~nm}$ ).

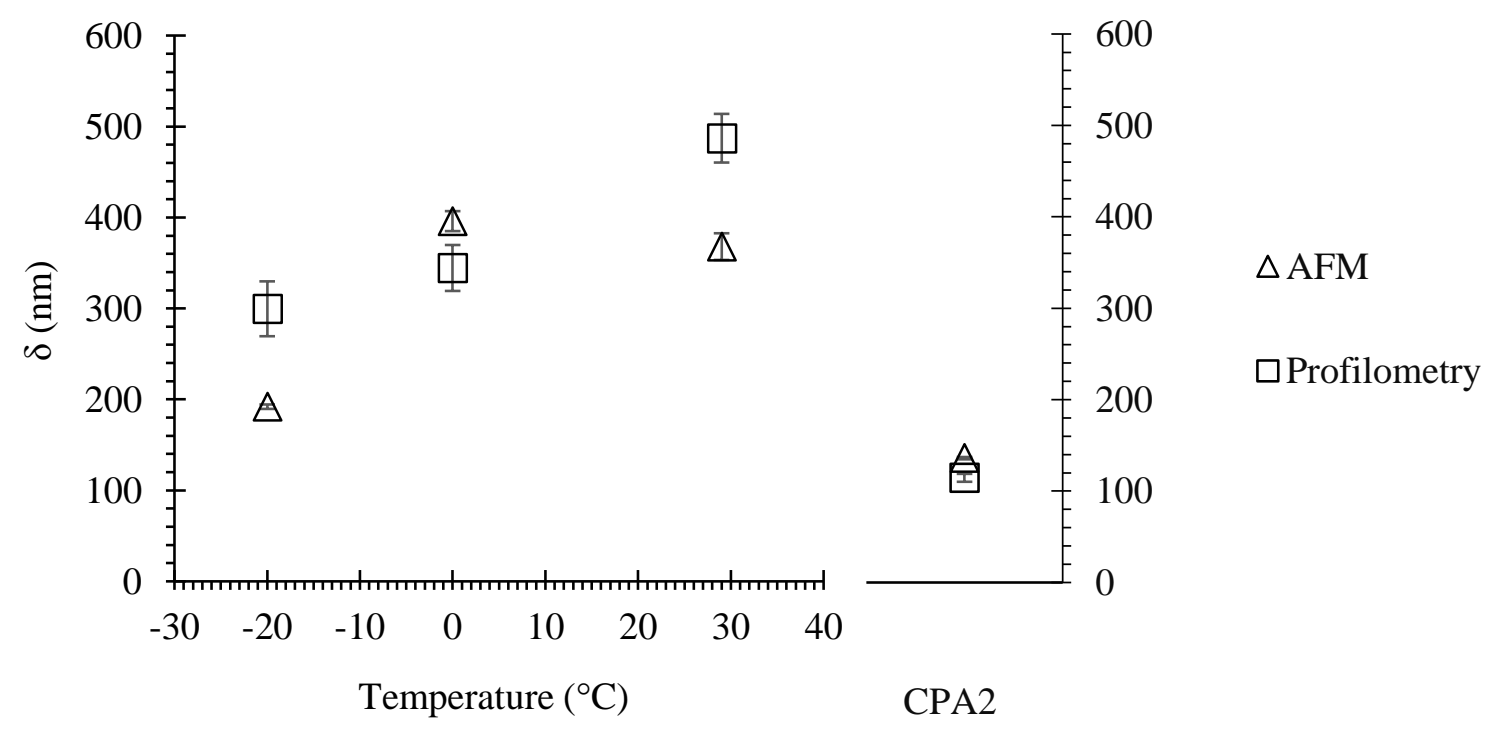

Figure 7. Top-surface thickness analysis via profilometry and AFM for Syn $-20{ }^{\circ} \mathrm{C}$, Syn $0{ }^{\circ} \mathrm{C}$, Syn $29^{\circ} \mathrm{C}$ and CPA2 samples. 


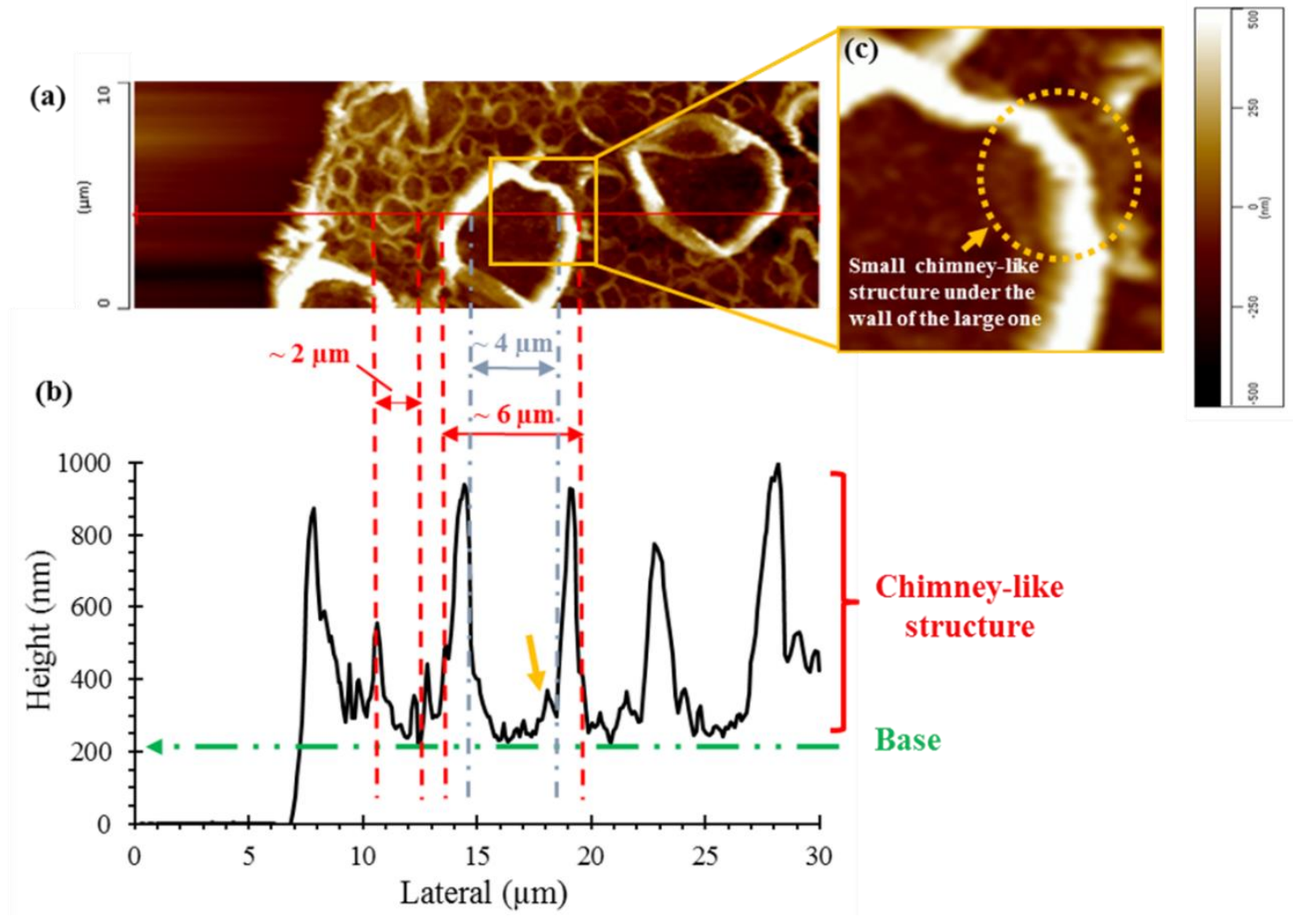

Figure 8. (a): AFM surface images of Syn $0{ }^{\circ} \mathrm{C}$ film; (b): corresponding AFM height profile along the red line; (c): corresponding enlarged image of the yellow solid box in image (a). (Total analyzed surface $\left.=30 \times 30 \mu \mathrm{m}^{2}\right)$.

\subsection{Water uptake, void fraction and density calculation}

Water uptake, voids fraction $\left(f_{\text {void }}\right)$, areal density $\left(d_{\text {areal }}\right)$, film effective volumetric density $\left(d_{\text {film }}\right)$ and density for dense APA region $\left(\mathrm{d}_{\mathrm{APA}}\right)$ are summarized in Table 2.

Synthesized APA films exhibit important water uptakes, up to $65 \%$. Such high values may be related to their high roughness, resulting in a much higher specific area than that of CPA2. It can be noticed that the smaller the chimneys diameters (at $-20^{\circ} \mathrm{C}$ ), the higher the specific area and water uptake are. Water uptake of APA from CPA2 is around $20 \%$, which is consistent with data reported by Lee et al. ${ }^{23}$ for SW30 or by Jiang et al. ${ }^{37}$ for synthesized APA films samples (12\% - $22 \%)$. The much shorter polymerization time used in the study of Jiang et al. ${ }^{37}$ 
(1 min versus 15 min for the present work) may explain the formation of a denser polymer, resulting in a much lower water uptake compared to that of the APA films we synthesized.

Areal density calculated for the synthesized samples appears 4 to 10 times higher than CPA2 one. The former should then be 4 to 10 times thicker compared to CPA2 to obtain a similar effective density $\mathrm{d}_{\text {film. }}$. This is obviously not the case (Table 1). For CPA2 APA layer and since no significant swelling took place, thickness values from Table 1 were considered and led to $d_{\text {film }}=0.7 \mathrm{~g} \cdot \mathrm{cm}^{-3}$ when dry and $1 \mathrm{~g} \cdot \mathrm{cm}^{-3}$ when hydrated. Values obtained for the synthesized samples are much higher and even sometimes unrealistic (up to $3.6 \mathrm{~g} \cdot \mathrm{cm}^{-3}$ ).

Due to their pronounced surface roughness, ellipsometry was found not suitable for analyzing the synthesized samples. Their void fraction and consecutively density of the dense APA phase therefore could not be determined. Similar difficulty had already been reported by Zhang et $a{ }^{56}$ for FT30 membranes due to their roughness. For CPA2 sample, using for example $\delta_{\text {Pro }}=115 \mathrm{~nm}, \mathrm{n}_{\text {film }}$ was measured at $1.40 \pm 0.01$, which is consistent with the few $n_{\text {film }}$ values published for commercial RO membranes: 1.48 for XLE and 1.43 for ESPA3's active layers. ${ }^{34}$ The refractive index of the sample's continuous phase $\left(n_{\text {polymer, }}\right.$ here $\left.n_{\text {APA }}\right)$ as well as that of included air $\left(n_{\text {air }}\right)$ are required (Eq 3 to 5$)$ to calculate $f_{\text {void. }}$ However, very few values of $n_{\text {APA }}$ have been reported previously hence three values were tested here: (i) a theoretical estimation at 1.7 based on a group-contribution method ${ }^{57}$ used in different studies ${ }^{11,58}$ and two estimations via Cauchy model constants on assumed dense nano-films : (ii) 1.6 calculated from Karan et al. ${ }^{32}$ and (iii) 1.74 from Dennison et al.'s calculation. ${ }^{39}$ The resulting CPA2 void fraction appears strongly dependent at the same time on this parameter and on the EMA model, with values varying between $23 \%$ and 59 \% (Figure 9). Considering Dennison et al.'s ${ }^{39}$ most recent value $\left(\mathrm{n}_{\mathrm{APA}}=1.74\right)$ and the Series EMA model, a void fraction lying between $33 \%$ (for $\delta_{\text {Pro }}=115 \mathrm{~nm}$ ) and $38 \%$ (for $\delta_{\text {AFM }}=136 \mathrm{~nm}$ ) was found for APA film in CPA2, in agreement with the work of Lin et al., ${ }^{34}$ where it was estimated between $21 \%$ and $39 \%$ for XLE and ESPA3 RO membranes. 
Considering an average void fraction of 35\% (determined by averaging AFM and profilometry values), a first experimental estimation of $d_{A P A}$ for commercial membranes is obtained, about $1.24 \mathrm{~g} \cdot \mathrm{cm}^{-3}$ when dry and $1.48 \mathrm{~g} \cdot \mathrm{cm}^{-3}$ when hydrated. The dry value is consistent with experimental determination made on dense support-free synthesized nano-films by Dennison et al ${ }^{39}$ and Karan et al. ${ }^{32}$ with the largest densities of $1.26 \mathrm{~g} \cdot \mathrm{cm}^{-3}$ and $1.44 \mathrm{~g} \cdot \mathrm{cm}^{-3}$ respectively. Besides, it is in agreement with APA density calculation from molecular modeling studies, ${ }^{59,60}$ of around $1.2 \mathrm{~g} \cdot \mathrm{cm}^{-3}$ for dry samples.

Table 2. Density estimation of APA active layer of CPA2 and synthesized APA film with thickness analyzed with profilometry and AFM

\begin{tabular}{|c|c|c|c|c|c|c|}
\hline Membrane & $\begin{array}{c}f_{\text {void }}(\%)^{a} \\
\text { Pro / AFM }\end{array}$ & $\underset{(\%)^{\mathbf{b}}}{\mathbf{R H}}$ & $\begin{array}{c}d_{\text {areal }} \\
\left(\mu \mathrm{g} \cdot \mathrm{cm}^{-2}\right)\end{array}$ & $\begin{array}{c}\text { Water } \\
\text { uptake } \\
(\%, w / w \\
\text { dry basis) }\end{array}$ & $\begin{array}{c}\mathbf{d}_{\text {film }}\left(\mathbf{g} \cdot \mathbf{c m}^{-3}\right) \\
\text { Pro / AFM }\end{array}$ & $\begin{array}{c}\mathrm{d}_{\text {APA }}\left(\mathbf{g} \cdot \mathrm{cm}^{-3}\right) \\
\text { Pro / AFM }\end{array}$ \\
\hline \multirow{2}{*}{ CPA2 } & \multirow{2}{*}{$33 \pm 1 / 38 \pm 4$} & 0 & $10.0 \pm 0.5$ & \multirow[b]{2}{*}{19} & $0.87 \pm 0.08 / 0.74 \pm 0.04$ & $1.30 \pm 0.14 / 1.18 \pm 0.14$ \\
\hline & & 88 & $11.9 \pm 0.6$ & & $1.04 \pm 0.09 / 0.88 \pm 0.05$ & $1.55 \pm 0.16 / 1.40 \pm 0.17$ \\
\hline \multirow{2}{*}{ Syn $-20^{\circ} \mathrm{C}$} & \multirow{2}{*}{ NA } & 0 & $42.1 \pm 2.1$ & & $1.41 \pm 0.21 / 2.19 \pm 0.13$ & NA \\
\hline & & 91 & $69.5 \pm 3.5$ & 65 & $2.32 \pm 0.35 / 3.62 \pm 0.22$ & NA \\
\hline \multirow{2}{*}{ Syn $0^{\circ} \mathrm{C}$} & \multirow{2}{*}{ NA } & 0 & $67.1 \pm 3.4$ & & $1.95 \pm 0.24 / 1.69 \pm 0.13$ & NA \\
\hline & & 92 & $90.9 \pm 4.6$ & 36 & $2.64 \pm 0.33 / 2.30 \pm 0.18$ & NA \\
\hline \multirow{2}{*}{ Syn $29^{\circ} \mathrm{C}$} & \multirow{2}{*}{ NA } & 0 & $81.3 \pm 4.1$ & & $1.67 \pm 0.18 / 2.21 \pm 0.20$ & NA \\
\hline & & 92 & $112.0 \pm 5.6$ & 38 & $2.30 \pm 0.24 / 3.04 \pm 0.28$ & NA \\
\hline
\end{tabular}

a Estimated from ellipsometry analysis and Series EMA model (with $\mathrm{n}_{\text {polymer }}=1.74$ ).

${ }^{b}$ No swelling took place between $0 \%$ and $92 \% \mathrm{RH}$. 


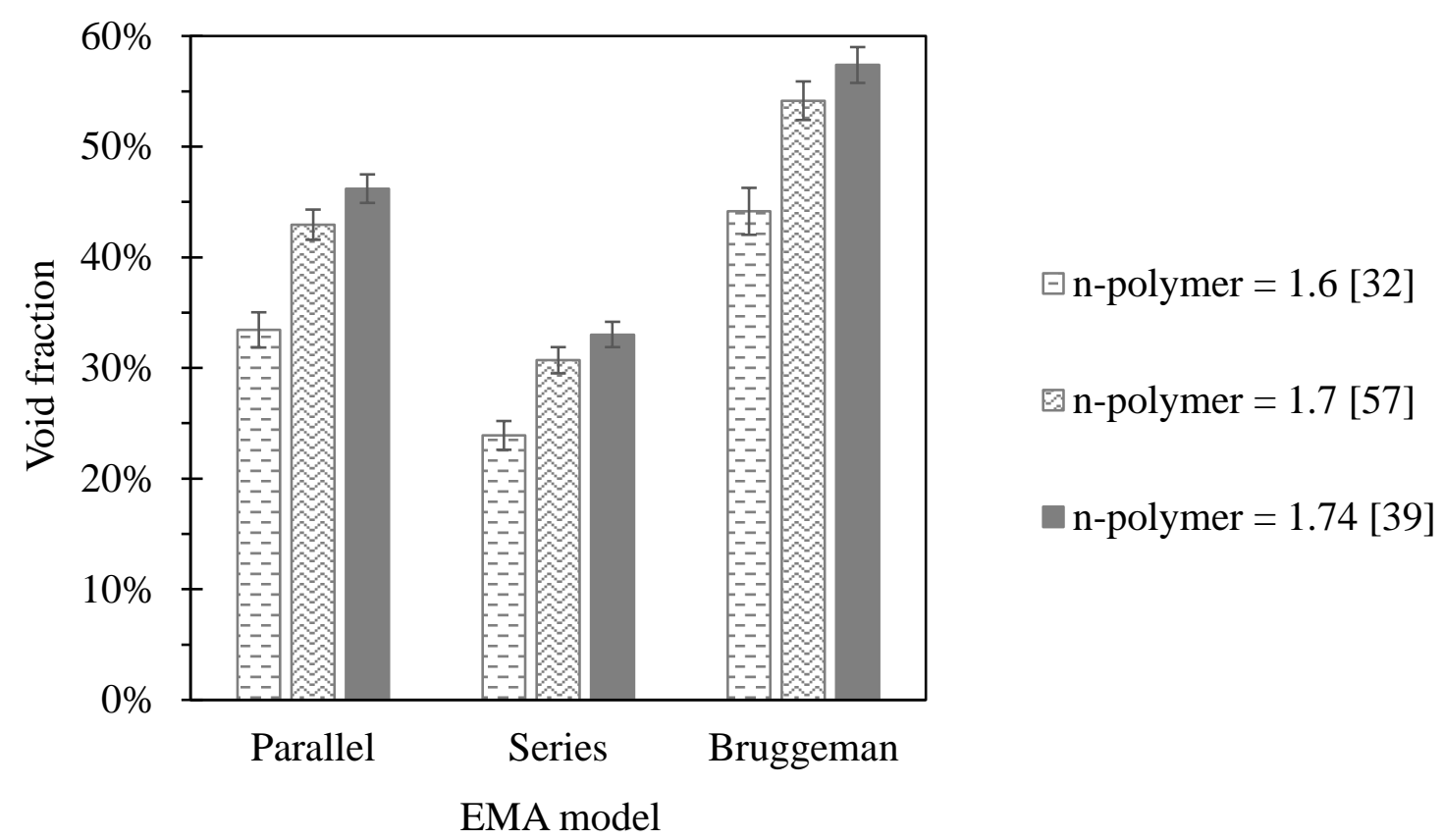

Figure 9. Void fraction estimation via EMA models for CPA2 APA film for various $\mathrm{n}_{\text {polymer }}$ data $\left(=\mathrm{n}_{\mathrm{APA}}\right)$ and for $\delta_{\mathrm{Pro}}=115 \mathrm{~nm}$.

$\mathrm{d}_{\text {film }}$ values higher than $1.2 \mathrm{~g} \cdot \mathrm{cm}^{-3}$ while they include voids, as observed for all the synthesized samples here, seem therefore questionable. Values up to $1.53 \mathrm{~g} \cdot \mathrm{cm}^{-3}$ were also found for other APA samples from uncoated and fully aromatic commercial membranes. ${ }^{33}$ For free-standing synthesized APA dense nano-films, $d_{\text {film }}$ values can be deduced from the properties reported in the supporting information of Jiang et al., ${ }^{37}$ and generally range from 1.2 to $1.6 \mathrm{~g}^{\cdot \mathrm{cm}^{-3}}$. Nonetheless, values as high as $2.1 \mathrm{~g} \cdot \mathrm{cm}^{-3}$ for the rougher films also arise. In all of these cases, excessive densities may be attributed to an under-estimation of the APA film thickness, due to its extremely uneven surface.

The above comparative analysis highlights that even sophisticated characterization methods have limitations in this context, due to the APA sample's high heterogeneity ${ }^{22}$ and very low thickness. ${ }^{33}$ They may only shed light to a partial or blurred sample structure. 


\subsection{Discussion on chemical structure of CPA2 membrane}

Elemental XPS analyses were used to gain information about the chemical structure of the APA sample from CPA2. Further analyses for synthesized samples still need to be conducted before publication.

\subsubsection{From composition data to chemical structure}

In this work, we propose an original approach based on new descriptors for improving the characterization of the APA chemical structure by going beyond the classical cross-linking degree descriptor. The polymer matrix is typically represented as a combination of two chemical units, the cross-linked units $X$, and the linear units $Y$ (Figure 10).
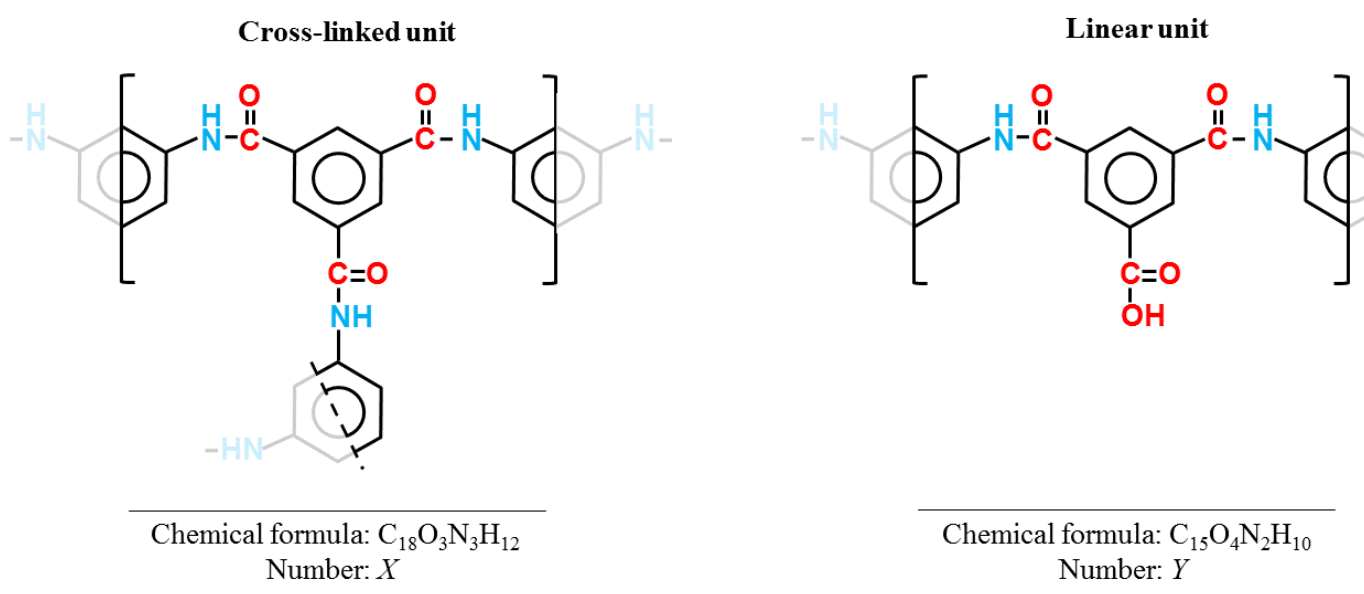

Figure 10. Chemical units in the conventional scheme for APA.

The APA cross-linking degree, $\chi$, is generally expressed as a function of the oxygen to nitrogen ratio, $\mathrm{O} / \mathrm{N}:{ }^{21,32,61,62}$

$$
\chi=\frac{X}{X+Y}=\frac{6}{1+\frac{\mathrm{O}}{\mathrm{N}}}-2
$$

It assumes that chain heads and tails (TMC or MPD monomers with at least one unreacted amine or acyl group) and branches (short chains connected to the main backbone) have a negligible effect on the chemical composition of the system. A perfect and fully cross-linked APA should then have a repeat unit molecular formula $\mathrm{C}_{18} \mathrm{O}_{3} \mathrm{~N}_{3} \mathrm{H}_{12}$ (unit $X$, Figure 10) 
corresponding to an $\mathrm{O} / \mathrm{N}$ ratio equals to 1 and a carbon fraction (excluding hydrogen atoms, not quantifiable by XPS) equal to 0.75 . A fully linear APA will have a repeating unit molecular formula $\mathrm{C}_{15} \mathrm{O}_{4} \mathrm{~N}_{2} \mathrm{H}_{10}$ (unit $Y$, Figure 10) corresponding to an $\mathrm{O} / \mathrm{N}$ ratio equal to 2 and a carbon fraction equals to 0.714 .

However, $\mathrm{O} / \mathrm{N}$ ratio is not a fully distinctive criterion as different structures can be observed with identical $\mathrm{O} / \mathrm{N}$ ratios. Furthermore, real systems include chain ends and branches such that their composition varies between the limits imposed by the fully linear and fully crosslinked structures. In order to quantify the relative populations of chain heads, tails and branches from the XPS analyses, we introduce a new set of four chemical units: TMC unit; MPD unit; hydroxyl terminal unit belonging to an unreacted TMC acid group; hydrogen terminal unit belonging to an unreacted MPD amine group. Their number is $a, b, c$, and $d$, respectively (Figure 11).

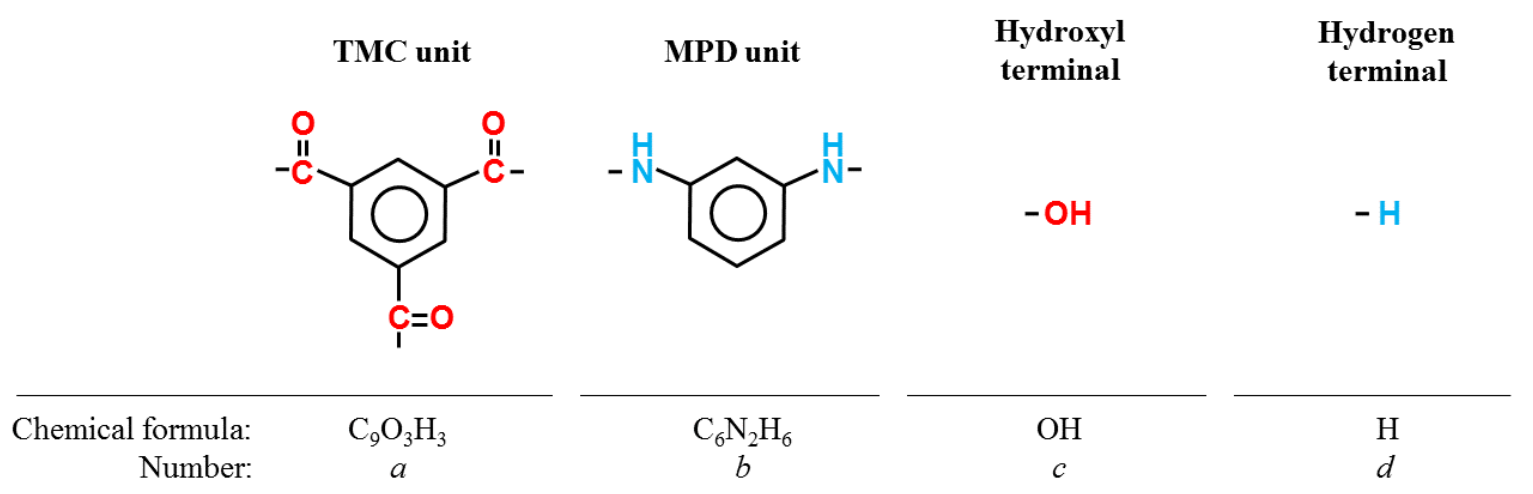

Figure 11. Chemical units in the new scheme for APA.

These quantities can be related to the elemental composition using the simple relations $\mathrm{C}=$ $9 a+6 b, O=3 a+c$ and $N=2 b$. Furthermore, for TMC and MPD backbones, their quantities of amide bond should be equal, hence we have: $2 b-d=3 a-c$. The fraction of acyl groups that have reacted, $f_{\mathrm{ac}}$, is given by the number of amide bonds divided by the maximal number of amide bonds that could have been formed for a number $a$ of TMC units: 


$$
f_{\mathrm{ac}}=\frac{3 a-c}{3 a}=\left(2-\frac{3 \mathrm{O}}{\mathrm{C}-3 \mathrm{~N}}\right)
$$

The fraction of amine groups that have reacted, $f_{\mathrm{am}}$, is given by the number of amide bonds divided by the maximal number of amide bonds that could have been formed for a number $b$ of MPD units:

$$
f_{\mathrm{am}}=\frac{2 b-d}{2 b}=\left(\frac{2 \mathrm{C}-3 \mathrm{O}}{3 \mathrm{~N}}-2\right)
$$

Finally, the TMC/MPD units' ratio, $r_{\mathrm{t}: \mathrm{m}}$, is simply given by this expression

$$
r_{\mathrm{t}: \mathrm{m}}=\frac{a}{b}=\left(\frac{2 \mathrm{C}-6 \mathrm{~N}}{9 \mathrm{~N}}\right)
$$

\subsubsection{XPS analysis data and chemical structure of APA layers}

The average $\mathrm{C} / \mathrm{O} / \mathrm{N}$ composition obtained from XPS analysis of CPA2 roughly equals 72/16/12 (Table 3). Within the 95\% confidence interval, no definite compositional difference is seen between original and dissected CPA2-ts, showing that the dissection did not modify the membrane chemical structure. On the contrary, a clear difference is observed between topand back- surfaces: the top-surface is richer in carbon and oxygen elements and poorer in nitrogen element. This difference had already been mentioned in the literature ${ }^{38}$ and attributed to a decreasing MPD concentration from the bottom up. It impacts the $\mathrm{O} / \mathrm{N}$ ratio, leading to a much higher cross-linking degree for its back-surface $\left(\chi_{b s} \approx 0.97\right)$ than for its top-surface $\left(\chi_{t s} \approx 0.45\right)$. A different conclusion emerges from the evolution of $f_{\mathrm{ac}}, f_{\mathrm{am}}$ and $r_{\mathrm{t}: \mathrm{m}}$, with much lower fractions of connected acyl and amine groups on the back-surface, then less "crosslinked": from back- to top-surface, the TMC/MPD monomeric units' ratio $\left(r_{\mathrm{t}: \mathrm{m}}\right)$ increases as a result of the decrease of MPD concentration along the thickness of the membrane, ${ }^{38}$ while TMC and MPD become better connected, with less unreacted amine and acyl groups on the top-surface. As emphasized by Morgan and Kwolek (1959), ${ }^{63}$ during interfacial polymerization acid chloride groups hydrolysis may occur at the interface where the contact with water molecules is possible. This process becomes competitive and consequently alters the cross- 
linking density. ${ }^{21}$ Thus, the lesser connectivity and larger amount of carboxyl groups observed at the back-surface could be due to this process.

Table 3. Chemical composition and chemical descriptors of CPA2 active layers

\begin{tabular}{|c|c|c|c|c|c|c|c|c|}
\hline CPA2 layer & C\% & $0 \%$ & $\mathrm{~N} \%$ & $\mathrm{O} / \mathrm{N}$ & $\chi$ & $f_{\mathrm{ac}}$ & $f_{\mathrm{am}}$ & $r_{\mathrm{t}: \mathrm{m}}$ \\
\hline $\begin{array}{c}\text { Original } \\
\text { top-surface }\end{array}$ & $\begin{array}{c}72.1 \\
( \pm 0.8)\end{array}$ & $\begin{array}{c}17.0 \\
( \pm 0.9)\end{array}$ & $\begin{array}{c}10.9 \\
( \pm 0.5)\end{array}$ & $\begin{array}{c}1.56 \\
( \pm 0.16)\end{array}$ & $\begin{array}{c}0.34 \\
( \pm 0.14)\end{array}$ & $\begin{array}{c}0.70 \\
( \pm 0.15)\end{array}$ & $\begin{array}{c}0.84 \\
( \pm 0.26)\end{array}$ & $\begin{array}{c}0.80 \\
( \pm 0.08)\end{array}$ \\
\hline CPA2-ts & $\begin{array}{c}73.1 \\
( \pm 0.5)\end{array}$ & $\begin{array}{c}15.4 \\
( \pm 0.4)\end{array}$ & $\begin{array}{c}11.5 \\
( \pm 0.4)\end{array}$ & $\begin{array}{c}1.34 \\
( \pm 0.08)\end{array}$ & $\begin{array}{c}0.57 \\
( \pm 0.08)\end{array}$ & $\begin{array}{c}0.80 \\
( \pm 0.08)\end{array}$ & $\begin{array}{c}0.90 \\
( \pm 0.16)\end{array}$ & $\begin{array}{c}0.75 \\
( \pm 0.06)\end{array}$ \\
\hline CPA2-bs & $\begin{array}{c}70.3 \\
( \pm 0.4)\end{array}$ & $\begin{array}{c}15.0 \\
( \pm 0.4)\end{array}$ & $\begin{array}{c}14.7 \\
( \pm 0.4)\end{array}$ & $\begin{array}{c}1.02 \\
( \pm 0.05)\end{array}$ & $\begin{array}{c}0.97 \\
( \pm 0.08)\end{array}$ & $\begin{array}{c}0.28 \\
( \pm 0.15)\end{array}$ & $\begin{array}{c}0.16 \\
( \pm 0.10)\end{array}$ & $\begin{array}{c}0.40 \\
( \pm 0.03)\end{array}$ \\
\hline
\end{tabular}

The possibility of having different chemical structures and compositions across the APA layer thickness has already been suggested by Freger and Srebnik, and Freger (2003) ${ }^{22,64}$ and studied in details recently by Coronell et al. ${ }^{38}$ But there again, opposite conclusions on the cross-linking evolution over thickness arise whether $\chi$ or the new descriptors are considered. Indeed, $\mathrm{O} / \mathrm{N}$ ratios, cross-linking degree $\chi$ and structural descriptors $f_{\mathrm{ac}}, f_{\mathrm{am}}$ and $r_{\mathrm{t}: \mathrm{m}}$ values can be deduced from their chemical compositions analyses, run for several RO membranes with XPS experiments for top-surface and Rutherford backscattering spectrometry (RBS) for volume-bulk (Table 4). Larger O/N ratio being measured by XPS than by RBS, the cross-linking degree $\chi$ appears lower on top-surfaces than in the bulk, as for our CPA2 samples. Meanwhile, structural descriptors $f_{\mathrm{ac}}, f_{\mathrm{am}}$ and $r_{\mathrm{t}: \mathrm{m}}$ lead to an opposite conclusion, as they indicate a stronger connectivity between MPD and TMC groups on top-surfaces than for the bulk.

This highlights that the cross-linking degree $\chi$, which assumes that no chain ends or defect exist in the polymer structure must be considered with care and is probably not suitable for the representation of APA in CPA2 membrane. 
Table 4 Chemical structure descriptors calculation for APA active layers from Coronell et al. (2011) ${ }^{38}$

\begin{tabular}{|l|c|c|c|c|c|}
\hline Active layer & $\mathrm{O} / \mathrm{N}$ & $\chi$ & $f_{\mathrm{ac}}$ & $f_{\mathrm{am}}$ & $r_{\mathrm{t}: \mathrm{m}}$ \\
\hline ESPA3 top-surface & 1.25 & 0.66 & 0.98 & 1.20 & 0.82 \\
\hline ESPA3 volume & 1.10 & 0.86 & 0.71 & 0.60 & 0.57 \\
\hline ESPAB top-surface & 1.46 & 0.44 & 0.87 & 1.13 & 0.86 \\
\hline ESPAB volume & 1.0 & 1.00 & 0.86 & 0.75 & 0.58 \\
\hline SWC5 top-surface & 1.10 & 0.86 & 1.28 & 1.94 & 1.01 \\
\hline SWC5 volume & 1.02 & 0.98 & 0.86 & 0.77 & 0.60 \\
\hline NF90 top-surface & 1.25 & 0.66 & 1.10 & 1.53 & 0.93 \\
\hline NF90 volume & 1.10 & 0.85 & 0.89 & 0.88 & 0.66 \\
\hline
\end{tabular}

\section{CONCLUSION}

The separation and very low thickness of the active layer of commercial RO membranes make its characterization difficult. The CPA2 membrane from Hydranautics was chosen here as a case-study, as it had been studied in our team for its rejection of several organic solutes. The structure of its aromatic polyamide layer (APA) can be considered representative for many other uncoated and fully aromatic reverse osmosis commercial membranes.

As already observed, the top-surface of CPA2 active layer exhibited a typical valley-ridge aspect developed on a base of $40 \mathrm{~nm}$ thick, while its back-surface was "flat". Its height was estimated at $115 \mathrm{~nm}$ with profilometry and $136 \mathrm{~nm}$ with AFM. Thanks to its thinner tip that could investigate more precisely the narrowest and deepest cavities, AFM was found more suitable to evaluate its top-surface roughness $(63 \pm 2 \mathrm{~nm})$. The void fraction in this polymer was found between $33 \%$ and $38 \%$ through combination of thickness and ellipsometry analyses, which allowed to deduce for the first time to our knowledge, a realistic volumetric density of the sole APA dense polymer of a commercial membrane, about $1.48 \mathrm{~g} . \mathrm{cm}^{-3}$ when hydrated and 1.24 g. $\mathrm{cm}^{-3}$ when dry. The latter value is in good agreement with the few existing data on synthesized APA, as well as with molecular simulation predictions. 
XPS analysis of CPA2 active layer showed a clear compositional difference between top- and back-surface. An original analysis based on new chemical structure descriptors $\left(f_{\mathrm{ac}}, f_{\mathrm{am}}\right.$ and $\left.r_{\mathrm{t}: \mathrm{m}}\right)$ accounting for chain heads, tails and branches resulting from non-ideal polymerization provided a better insight into its chemical structure, compared to the classical cross-linking degree. A striking result is that different types of descriptors led to opposite conclusions: while cross-linking degree $\chi$ suggested that CPA2 APA back-surface was more cross-linked than the top, the new chemical structure descriptors showed the contrary, with a lower connectivity rate at the back-surface than that on the top. The cross-linking degree $\chi$ was then considered unsuitable to describe this polymer and should be limited to systems with negligible amounts of chain branching, heads and tails.

In order to compare different controlled structures, APA films synthesized using free-standing interfacial polymerization at different temperatures were studied. The morphology of their top surface was significantly different from that of the commercial CPA2: AFM allowed to distinguish a "base" above which developed hollow cylindrical walls or "chimneys", whose size tended to increase with synthesis temperature, as did the average sample thickness, from about $250 \mathrm{~nm}$ at $-20{ }^{\circ} \mathrm{C}$ up to $450 \mathrm{~nm}$ at $29{ }^{\circ} \mathrm{C}$. These samples were so uneven that ellipsometry technique was unsuitable. Consequently, their void fraction and density could not be calculated.

Our study emphasizes that although density is a very standard property, it remains very difficult to obtain with high accuracy for such complex multilevel structures. An accurate description of their chemical structure such as the cross-linking state appears to be also a challenge in itself, which needs the purest samples and the most precise methods. 
TOC /Abstract graphic

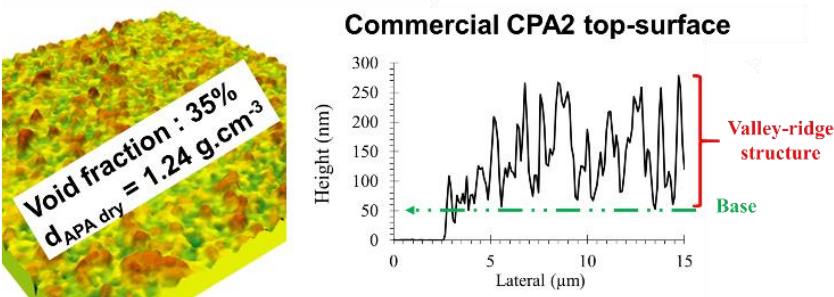

- C/O/N elements : 72/16/12 (XPS).

- Stronger connectivity between MPD and TMC groups on top-surface than on back surface, contrary to the cross-linking degree evolution. 


\section{REFERENCES}

(1) Shenvi, S. S.; Isloor, A. M.; Ismail, A. F. A Review on RO Membrane Technology: Developments and Challenges. Desalination 2015, 368, 10-26.

(2) Frenzel, I.; Stamatialis, D. F.; Wessling, M. Water Recycling from Mixed Chromic Acid Waste Effluents by Membrane Technology. Sep. Purif. Technol. 2006, 49 (1), 76-83.

(3) Hoinkis, J.; Panten, V. Wastewater Recycling in Laundries-From Pilot to Large-Scale Plant. Chem. Eng. Process. Process Intensif. 2008, 47 (7), 1159-1164.

(4) Sagne, C.; Fargues, C.; Lewandowski, R.; Lameloise, M. L.; Gavach, M.; Decloux, M. A Pilot Scale Study of Reverse Osmosis for the Purification of Condensate Arising from Distillery Stillage Concentration Plant. Chem. Eng. Process. Process Intensif. 2010, 49 (4), 331-339.

(5) Al-Bastaki, N. M. Performance of Advanced Methods for Treatment of Wastewater: UV/TiO2, RO and UF. Chem. Eng. Process. Process Intensif. 2004, 43 (7), 935-940.

(6) Sonune, A.; Ghate, R. Developments in Wastewater Treatment Methods. Desalination 2004, 167, 55-63.

(7) Li, C.; Yang, Y.; Liu, Y.; Hou, L. Removal of PhACs and Their Impacts on Membrane Fouling in NF/RO Membrane Filtration of Various Matrices. J. Memb. Sci. 2018, 548, 439-448.

(8) Licona, K. P. M.; Geaquinto, L. R. d. O.; Nicolini, J. V.; Figueiredo, N. G.; Chiapetta, S. C.; Habert, A. C.; Yokoyama, L. Assessing Potential of Nanofiltration and Reverse Osmosis for Removal of Toxic Pharmaceuticals from Water. J. Water Process Eng. 2018, 25, 195-204.

(9) Fini, M. N.; Madsen, H. T.; Muff, J. The Effect of Water Matrix, Feed Concentration and Recovery on the Rejection of Pesticides Using NF/RO Membranes in Water Treatment. Sep. Purif. Technol. 2019, 215, 521-527.

(10) Plakas, K. V.; Karabelas, A. J. Removal of Pesticides from Water by NF and RO Membranes - A Review. Desalination 2012, 287, 255-265.

(11) Ben-David, A.; Bason, S.; Jopp, J.; Oren, Y.; Freger, V. Partitioning of Organic Solutes between Water and Polyamide Layer of RO and NF Membranes: Correlation to Rejection. J. Memb. Sci. 2006, 281 (1-2), 480-490.

(12) Fargues, C.; Sagne, C.; Szymczyk, A.; Fievet, P.; Lameloise, M. L. Adsorption of Small Organic Solutes from Beet Distillery Condensates on Reverse-Osmosis Membranes: Consequences on the Process Performances. J. Memb. Sci. 2013, 446, 132-144.

(13) Ghoufi, A.; Dražević, E.; Szymczyk, A. Interactions of Organics within Hydrated Selective Layer of Reverse Osmosis Desalination Membrane: A Combined Experimental and Computational Study. Environ. Sci. Technol. 2017, 51 (5), 27142719.

(14) Liu, Y.; Wang, X.; Yang, H.; Xie, Y. F. Quantifying the Influence of Solute-Membrane Interactions on Adsorption and Rejection of Pharmaceuticals by NF/RO Membranes. J. Memb. Sci. 2018, 551, 37-46.

(15) Nghiem, L. D.; Schäfer, A. I.; Elimelech, M. Removal of Natural Hormones by Nanofiltration Membranes: Measurement, Modeling, and Mechanisms. Environ. Sci. Technol. 2004, 38 (6), 1888-1896.

(16) Bellona, C.; Drewes, J. E.; Xu, P.; Amy, G. Factors Affecting the Rejection of Organic 
Solutes during NF/RO Treatment - A Literature Review. Water Res. 2004, 38 (12), 2795-2809.

(17) Soltanieh, M.; Gill, W. N. Review of Reverse Osmosis Membranes and Transport Models. Chem. Eng. Commun. 1981, 12 (4-6), 279-363.

(18) Wijmans, J. G.; Baker, R. W. The Solution-Diffusion Model: A Review. J. Memb. Sci. 1995, 107, 1-21.

(19) Williams, M. E.; Hestekin, J. A.; Smothers, C. N.; Bhattacharyya, D. Separation of Organic Pollutants by Reverse Osmosis and Nanofiltration Membranes: Mathematical Models and Experimental Verification. Ind. Eng. Chem. Res. 1999, 38 (10), 3683-3695.

(20) Ettori, A. Vieillissement Chimique de Membranes d'osmose Inverse. Ph.D. Thesis, Université Toulouse III - Paul Sabatier, Toulouse, France, 2011.

(21) Khorshidi, B.; Thundat, T.; Fleck, B. A.; Sadrzadeh, M. A Novel Approach Toward Fabrication of High Performance Thin Film Composite Polyamide Membranes. Sci. Rep. 2016, 6 (1), 22069.

(22) Freger, V. Nanoscale Heterogeneity of Polyamide Membranes Formedby Interfacial Polymerization. Langmuir 2003, 19 (11), 4791-4797.

(23) Lee, J.; Doherty, C. M.; Hill, A. J.; Kentish, S. E. Water Vapor Sorption and Free Volume in the Aromatic Polyamide Layer of Reverse Osmosis Membranes. J. Memb. Sci. 2013, 425, 217-226.

(24) Yan, H.; Miao, X.; Xu, J.; Pan, G.; Zhang, Y.; Shi, Y.; Guo, M.; Liu, Y. The Porous Structure of the Fully-Aromatic Polyamide Film in Reverse Osmosis Membranes. J. Memb. Sci. 2015, 475, 504-510.

(25) Pacheco, F.; Sougrat, R.; Reinhard, M.; Leckie, J. O.; Pinnau, I. 3D Visualization of the Internal Nanostructure of Polyamide Thin Films in RO Membranes. J. Memb. Sci. 2016, 501, 33-44.

(26) Hermans, S.; Bernstein, R.; Volodin, A.; Vankelecom, I. F. J. Study of Synthesis Parameters and Active Layer Morphology of Interfacially Polymerized PolyamidePolysulfone Membranes. React. Funct. Polym. 2015, 86, 199-208.

(27) Tang, C. Y.; Kwon, Y.-N.; Leckie, J. O. Probing the Nano- and Micro-Scales of Reverse Osmosis Membranes-A Comprehensive Characterization of Physiochemical Properties of Uncoated and Coated Membranes by XPS, TEM, ATR-FTIR, and Streaming Potential Measurements. J. Memb. Sci. 2007, 287 (1), 146-156.

(28) Xu, J.; Yan, H.; Zhang, Y.; Pan, G.; Liu, Y. The Morphology of Fully-Aromatic Polyamide Separation Layer and Its Relationship with Separation Performance of TFC Membranes. J. Memb. Sci. 2017, 541, 174-188.

(29) Song, X.; Gan, B.; Yang, Z.; Tang, C. Y.; Gao, C. Confined Nanobubbles Shape the Surface Roughness Structures of Thin Film Composite Polyamide Desalination Membranes. J. Memb. Sci. 2019, 582, 342-349.

(30) Song, X.; Gan, B.; Qi, S.; Guo, H.; Tang, C. Y.; Zhou, Y.; Gao, C. Intrinsic Nanoscale Structure of Thin Film Composite Polyamide Membranes: Connectivity, Defects, and Structure--Property Correlation. Environ. Sci. Technol. 2020, 54 (6), 3559-3569.

(31) Peng, L. E.; Yao, Z.; Yang, Z.; Guo, H.; Tang, C. Y. Dissecting the Role of Substrate on the Morphology and Separation Properties of Thin Film Composite Polyamide Membranes: Seeing Is Believing. Environ. Sci. Technol. 2020, 54 (11), 6978-6986.

(32) Karan, S.; Jiang, Z.; Livingston, A. G. Sub-10 Nm Polyamide Nanofilms with Ultrafast 
Solvent Transport for Molecular Separation. Science. 2015, 348 (6241), 1347-1351.

(33) Lin, L.; Feng, C.; Lopez, R.; Coronell, O. Identifying Facile and Accurate Methods to Measure the Thickness of the Active Layers of Thin-Film Composite Membranes - A Comparison of Seven Characterization Techniques. J. Memb. Sci. 2016, 498, 167-179.

(34) Lin, L.; Lopez, R.; Ramon, G. Z.; Coronell, O. Investigating the Void Structure of the Polyamide Active Layers of Thin-Film Composite Membranes. J. Memb. Sci. 2016, 497, 365-376.

(35) Khorshidi, B.; Thundat, T.; Fleck, B. A.; Sadrzadeh, M. Thin Film Composite Polyamide Membranes: Parametric Study on the Influence of Synthesis Conditions. RSC Adv. 2015, 5 (68), 54985-54997.

(36) Tang, C. Y.; Kwon, Y.-N.; Leckie, J. O. Effect of Membrane Chemistry and Coating Layer on Physiochemical Properties of Thin Film Composite Polyamide RO and NF Membranes. I. FTIR and XPS Characterization of Polyamide and Coating Layer Chemistry. Desalination 2009, 242 (1-3), 149-167.

(37) Jiang, Z.; Karan, S.; Livingston, A. G. Water Transport through Ultrathin Polyamide Nanofilms Used for Reverse Osmosis. Adv. Mater. 2018, 30 (15), 1705973.

(38) Coronell, O.; Mariñas, B. J.; Cahill, D. G. Depth Heterogeneity of Fully Aromatic Polyamide Active Layers in Reverse Osmosis and Nanofiltration Membranes. Environ. Sci. Technol. 2011, 45 (10), 4513-4520.

(39) Dennison, J. M.; Xie, X.; Murphy, C. J.; Cahill, D. G. Density, Elastic Constants, and Thermal Conductivity of Interfacially Polymerized Polyamide Films for Reverse Osmosis Membranes. ACS Appl. Nano Mater. 2018, 1 (9), 5008-5018.

(40) Nguyen, N.; Fargues, C.; Guiga, W.; Lameloise, M.-L. Assessing Nanofiltration and Reverse Osmosis for the Detoxification of Lignocellulosic Hydrolysates. J. Memb. Sci. 2015, 487, 40-50.

(41) Gerard, R.; Hachisuka, H.; Hirose, M. New Membrane Developments Expanding the Horizon for the Application of Reverse Osmosis Technology. Desalination 1998, 119 (1-3), 47-55.

(42) Chen, Z.; Luo, J.; Hang, X.; Wan, Y. Physicochemical Characterization of Tight Nanofiltration Membranes for Dairy Wastewater Treatment. J. Memb. Sci. 2018, 547, 51-63.

(43) Sagne, C.; Fargues, C.; Broyart, B.; Lameloise, M. L.; Decloux, M. Modeling Permeation of Volatile Organic Molecules through Reverse Osmosis Spiral-Wound Membranes. J. Memb. Sci. 2009, 330 (1-2), 40-50.

(44) Sagne, C.; Fargues, C.; Lewandowski, R.; Lameloise, M.-L.; Decloux, M. Screening of Reverse Osmosis Membranes for the Treatment and Reuse of Distillery Condensates into Alcoholic Fermentation. Desalination 2008, 219 (1-3), 335-347.

(45) Freger, V. Swelling and Morphology of the Skin Layer of Polyamide Composite Membranes: An Atomic Force Microscopy Study. Environ. Sci. Technol. 2004, 38 (11), 3168-3175.

(46) Cui, Y.; Liu, X.-Y.; Chung, T.-S. Ultrathin Polyamide Membranes Fabricated from FreeStanding Interfacial Polymerization: Synthesis, Modifications, and Post-Treatment. Ind. Eng. Chem. Res. 2017, 56 (2), 513-523.

(47) Foglia, F.; Karan, S.; Nania, M.; Jiang, Z.; Porter, A. E.; Barker, R.; Livingston, A. G.; Cabral, J. T. Neutron Reflectivity and Performance of Polyamide Nanofilms for Water 
Desalination. Adv. Funct. Mater. 2017, 27 (37), 1701738.

(48) Jin, Y.; Su, Z. Effects of Polymerization Conditions on Hydrophilic Groups in Aromatic Polyamide Thin Films. J. Memb. Sci. 2009, 330 (1-2), 175-179.

(49) Dutta, D.; Bhattacharyya, A.; Ganguly, B. N. Microstructural Study of Aromatic Polyamide Membrane Material. J. Memb. Sci. 2003, 224 (1-2), 127-135.

(50) Greenspan, L. Humidity Fixed Points of Binary Saturated Aqueous Solutions. J. Res. Natl. Bur. Stand. (1934). 1977, 81A (1), 89-96.

(51) Kwak, S.-Y.; Ihm, D. W. Use of Atomic Force Microscopy and Solid-State NMR Spectroscopy to Characterize Structure-Property-Performance Correlation in High-Flux Reverse Osmosis (RO) Membranes. J. Memb. Sci. 1999, 158 (1-2), 143-153.

(52) Pacheco, F. A.; Pinnau, I.; Reinhard, M.; Leckie, J. O. Characterization of Isolated Polyamide Thin Films of RO and NF Membranes Using Novel TEM Techniques. J. Memb. Sci. 2010, 358 (1-2), 51-59.

(53) Li, Q.; Pan, X.; Hou, C.; Jin, Y.; Dai, H.; Wang, H.; Zhao, X.; Liu, X. Exploring the Dependence of Bulk Properties on Surface Chemistries and Microstructures of Commercially Composite RO Membranes by Novel Characterization Approaches. Desalination 2012, 292, 9-18.

(54) Nowbahar, A.; Mansard, V.; Mecca, J. M.; Paul, M.; Arrowood, T.; Squires, T. M. Measuring Interfacial Polymerization Kinetics Using Microfluidic Interferometry. J. Am. Chem. Soc. 2018, 140 (9), 3173-3176.

(55) Dražević, E.; Košutić, K.; Freger, V. Permeability and Selectivity of Reverse Osmosis Membranes: Correlation to Swelling Revisited. Water Res. 2014, 49, 444-452.

(56) Zhang, X.; Cahill, D. G.; Coronell, O.; Mariñas, B. J. Absorption of Water in the Active Layer of Reverse Osmosis Membranes. J. Memb. Sci. 2009, 331 (1-2), 143-151.

(57) Van Krevelen, D. W.; Te Nijenhuis, K. Optical Properties. In Properties of Polymers: Their Correlation with Chemical Structure; Their Numerical Estimation and Prediction from Additive Group Contributions, $4^{\text {th }}$ ed.; Elsevier: Amsterdam, the Netherlands, 2009; pp 290-296.

(58) Ben-David, A.; Oren, Y.; Freger, V. Thermodynamic Factors in Partitioning and Rejection of Organic Compounds by Polyamide Composite Membranes. Environ. Sci. Technol. 2006, 40 (22), 7023-7028.

(59) Kolev, V.; Freger, V. Hydration, Porosity and Water Dynamics in the Polyamide Layer of Reverse Osmosis Membranes: A Molecular Dynamics Study. Polymer (Guildf). 2014, 55 (6), 1420-1426.

(60) Shen, M.; Keten, S.; Lueptow, R. M. Rejection Mechanisms for Contaminants in Polyamide Reverse Osmosis Membranes. J. Memb. Sci. 2016, 509, 36-47.

(61) Akin, O.; Temelli, F. Probing the Hydrophobicity of Commercial Reverse Osmosis Membranes Produced by Interfacial Polymerization Using Contact Angle, XPS, FTIR, FE-SEM and AFM. Desalination 2011, 278 (1-3), 387-396.

(62) Kim, S. H.; Kwak, S.-Y.; Suzuki, T. Positron Annihilation Spectroscopic Evidence to Demonstrate the Flux-Enhancement Mechanism in Morphology-Controlled Thin-FilmComposite (TFC) Membrane. Environ. Sci. Technol. 2005, 39 (6), 1764-1770.

(63) Morgan, P. W.; Kwolek, S. L. Interfacial Polycondensation. II. Fundamentals of Polymer Formation at Liquid Interfaces. J. Polym. Sci. 1959, 40 (137), 299-327. 
(64) Freger, V.; Srebnik, S. Mathematical Model of Charge and Density Distributions in Interfacial Polymerization of Thin Films. J. Appl. Polym. Sci. 2003, 88 (5), 1162-1169. 


\section{Figures captions}

Figure 1. SEM image of CPA2 original APA top-surface.

Figure 2. AFM and SEM images of CPA2 APA layers.

Figure 3. AFM and SEM images of synthesized APA films' top-surface and back surface.

Figure 4. Influence of relative humidity on thickness measured by profilometry for the CPA2 samples.

Figure 5. Representative topography profiles of CPA2-ts via profilometry and AFM. Both analyses are realized on distinct sample frames.

Figure 6. (a): AFM surface images of CPA2-ts; (b): corresponding AFM height profile along the red line. (Analysis of a $10 \times 30 \mu \mathrm{m}^{2}$ half-covered sample).

Figure 7. Top-surface thickness analysis via profilometry and $A F M$ for Syn $-20^{\circ} \mathrm{C}$, Syn $0{ }^{\circ} \mathrm{C}$, Syn $29^{\circ} \mathrm{C}$ and CPA2 samples.

Figure 8. (a): AFM surface images of Syn $0{ }^{\circ} \mathrm{C}$ film; (b): corresponding AFM height profile along the red line; (c): corresponding enlarged image of the yellow solid box in image (a). (Total analyzed surface $\left.=30 \times 30 \mu \mathrm{m}^{2}\right)$.

Figure 9. Void fraction estimation via EMA models for CPA2 APA film for various $\mathrm{n}_{\text {polymer }}$ data $\left(=\mathrm{n}_{\text {APA }}\right)$ and for $\delta_{\text {Pro }}=115 \mathrm{~nm}$.

Figure 10. Chemical units in the conventional scheme for APA.

Figure 11. Chemical units in the new scheme for APA. 